\title{
Boron-10 Lined Proportional Counter Model Validation
}

Azaree Lintereur

Edward R. Siciliano

Richard T. Kouzes

June 2012

\section{Pacific Northwest}

NATIONAL LABORATORY

Proudly Operated by Battelle Since 1965 


\title{
DISCLAIMER
}

This report was prepared as an account of work sponsored by an agency of the United States Government. Neither the United States Government nor any agency thereof, nor Battelle Memorial Institute, nor any of their employees, makes any warranty, express or implied, or assumes any legal liability or responsibility for the accuracy, completeness, or usefulness of any information, apparatus, product, or process disclosed, or represents that its use would not infringe privately owned rights. Reference herein to any specific commercial product, process, or service by trade name, trademark, manufacturer, or otherwise does not necessarily constitute or imply its endorsement, recommendation, or favoring by the United States Government or any agency thereof, or Battelle Memorial Institute. The views and opinions of authors expressed herein do not necessarily state or reflect those of the United States Government or any agency thereof.

\author{
PACIFIC NORTHWEST NATIONAL LABORATORY \\ operated by \\ BATTELLE \\ for the \\ UNITED STATES DEPARTMENT OF ENERGY \\ under Contract DE-AC05-76RL01830
}

Printed in the United States of America
Available to DOE and DOE contractors from the
Office of Scientific and Technical Information,
P.O. Box 62, Oak Ridge, TN 37831-0062;
ph: (865) 576-8401
fax: (865) 576-5728
email: reports@adonis.osti.gov

Available to the public from the National Technical Information Service, U.S. Department of Commerce, 5285 Port Royal Rd., Springfield, VA 22161

ph: (800) 553-6847

fax: (703) 605-6900

email: orders@ntis.fedworld.gov

online ordering: http://www.ntis.gov/ordering.htm 
PNNL-21501

\section{Boron-10 Lined Proportional Counter Model Validation}

Azaree Lintereur

Edward R. Siciliano

Richard T. Kouzes

June 2012

Pacific Northwest National Laboratory

Richland, Washington 99352 


\section{Executive Summary}

The Department of Energy Office of Nuclear Safeguards (NA-241) is supporting the project "Coincidence Counting With Boron-Based Alternative Neutron Detection Technology" at Pacific Northwest National Laboratory (PNNL) for the development of an alternative neutron coincidence counter. The goal of this project is to design, build and demonstrate a boron-lined proportional tube-based alternative system in the configuration of a coincidence counter.

This report discusses the validation studies performed to establish the degree of accuracy of the computer modeling methods currently used to simulate the response of boron-lined tubes. This is the precursor to developing models for the uranium neutron coincidence collar under Task 2 of this project.

The strategy for this project going forward is to use the model parameters that provide adequate comparison to experiment, which may or may not be related to the actual material or thickness of the lining. No information from the vendor on the actual boron coating was used in this study. A boron metal thickness of $0.75 \mu \mathrm{m}$ appears to be an adequate value to use for models of boronlined tube systems based upon the current tubes supplied by General Electric Reuter-Stokes for testing. Good agreement between measurement and model was obtained for close geometries, though agreement was not as good at larger distances, where the models over predict response. This may indicate that the model of the room environment needs to be improved.

This work will be extended over the next several months to more comparisons of models to experiments to improve the agreement that can be obtained. The results from this work will be applied to the development of the coincidence collar models using boron-lined tubes. 


\section{Acronyms and Abbreviations}

DOE

GE

GEB

HDPE

LEC

NDM

PNNL
U.S. Department of Energy

General Electric

Gaussian Energy Broadening

High density polyethylene

Low-energy cutoff

Neutron detection module

Pacific Northwest National Laboratory 


\section{Contents}

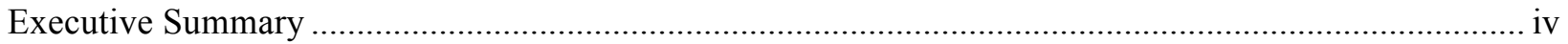

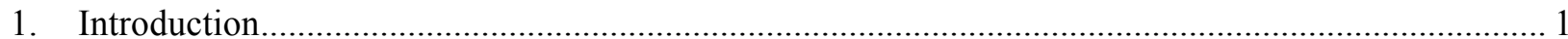

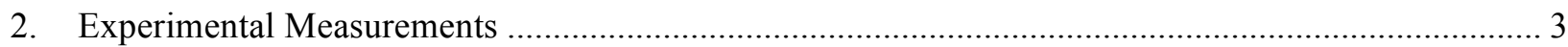

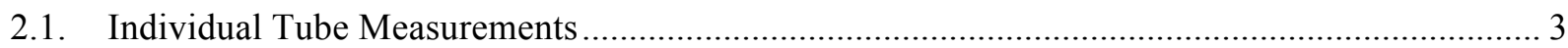

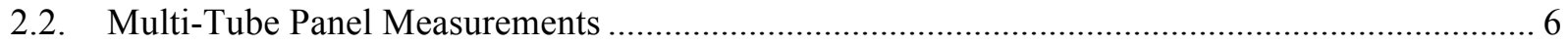

2.3. Measurements with an Assembly of Four Multi-Tube Panels ................................................... 9

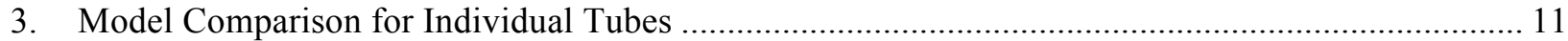

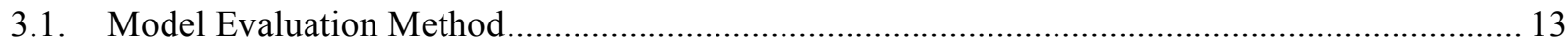

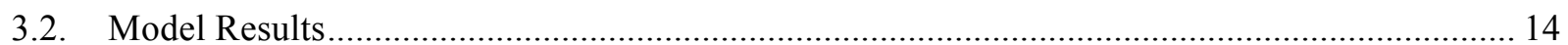

4. Model Comparison for the Multi-Tube Panel ................................................................................. 17

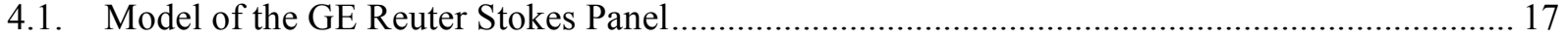

4.2. The Modeled Measurement Environment ................................................................................. 19

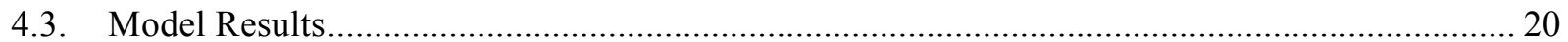

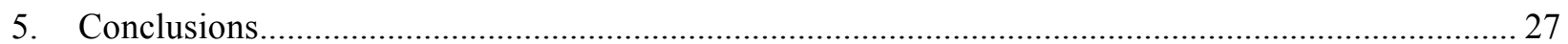

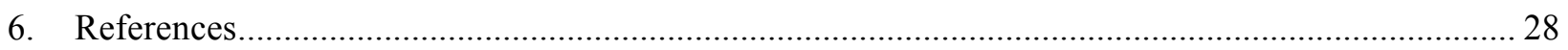

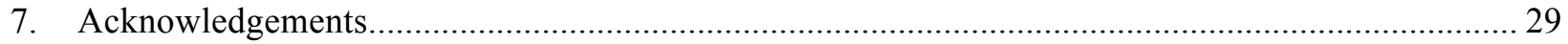

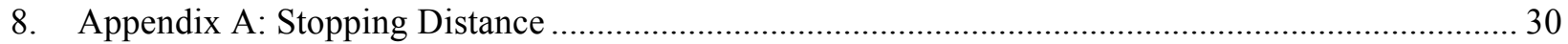

9. Appendix B: Complete Set of Moderated Single Tube Results ….................................................. 32

10. Appendix C: Complete set of Modeled Multiple Tube Panel Results............................................. 41 


\section{Figures and Tables}

\section{Figures}

Figure 1.1. Schematic of a GE Reuter Stokes ${ }^{10} \mathrm{~B}$-lined proportional counter (units are inches)............... 2

Figure 1.2. GE Reuter Stokes NDM "panel" containing an array of ${ }^{10} \mathrm{~B}$-lined proportional counters......... 2

Figure 2.1. Bare boron-lined tube on tripod (right) and source holder (left) in high bay......................... 3

Figure 2.2. Boron-lined tube inside polyethylene on tripod (left) and source holder (right) in high bay..... 4

Figure 2.3. Net bare boron-lined Tube 2 response $25 \mathrm{~cm}$ from the source acquired for $500 \mathrm{~s}$................... 5

Figure 2.4. Net moderated boron-lined Tube 2 response $25 \mathrm{~cm}$ from the source acquired for $500 \mathrm{~s}$.......... 5

Figure 2.5. Panel containing of boron-lined tubes on lift (right) and source holder (left) in high bay........ 7

Figure 2.6. Pulse-height spectra from panel 10HBN281 with source at various distances. ....................... 8

Figure 2.7. Three boron-lined tube panels on floor of the high bay. .................................................... 9

Figure 2.8. Four-panel configuration on floor of the high bay. ........................................................... 9

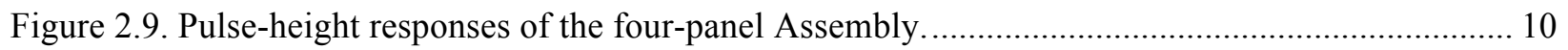

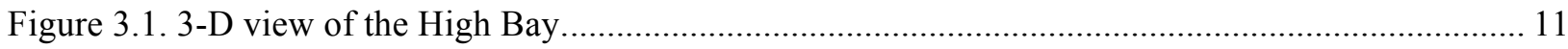

Figure 3.2. Schematic of source in the pig [source is the black cylinder inside the steel (green) case]..... 12

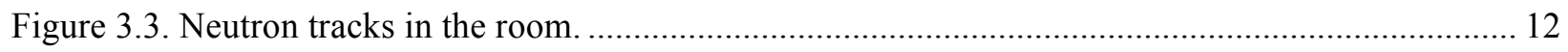

Figure 4.1. Screen captures showing cross-sectional views from the front (top) and end (bottom).......... 17

Figure 4.2. Three-dimensional projection of the modeling environment. .............................................. 19

Figure 4.3. Effects of Boron Metal Lining Thickness on Pulse-Height Spectra. .................................... 22

Figure 4.4. Effects of Boron Nitride Lining Thickness on Pulse-Height Spectra. .................................. 23

Figure 4.5. Effects of Boron Carbide Lining Thickness on Pulse-Height Spectra. ................................. 24

Figure 4.6. Effects on Pulse-Height Spectra from $\mathrm{CO}_{2}$ in Proportional Gas........................................ 25

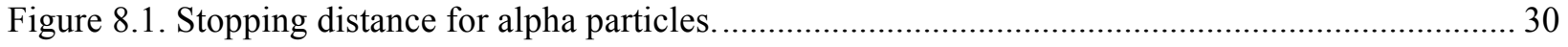

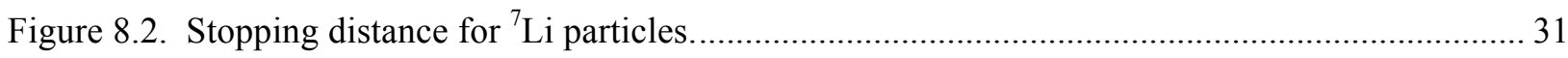

\section{Tables}

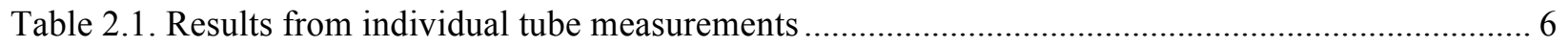

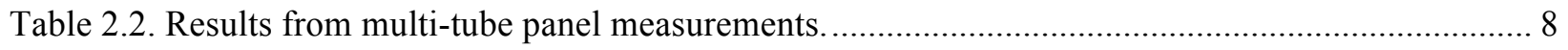

Table 2.3. Results from the four-panel Assembly measurements...................................................... 10

Table 3.1. Percent differences between models and measurements for moderated individual tubes......... 15

Table 3.2. Percent differences between simulations and measurements for the moderated individual tubes

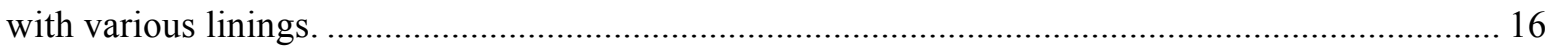


Table 4.1. Percent differences between the panel model and measurements as a function of boron metal

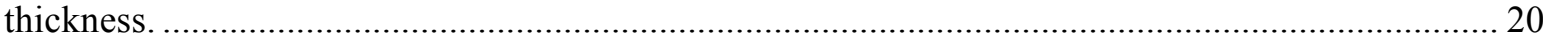

Table 4.2. Percent differences for panel model efficiency as a function of boron lining material............ 21

Table 9.1. Moderated single tube model results for boron metal linings and comparison to experiment. . 32

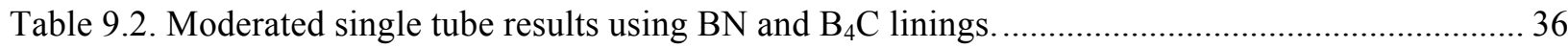

Table 9.3. Results of simulations compared to measurements for moderated individual tubes................ 38

Table 9.4. Results of simulations compared to measurements for moderated individual tubes................ 40

Table 10.1. Model compared to experiment efficiency as a function of boron metal thickness and low-

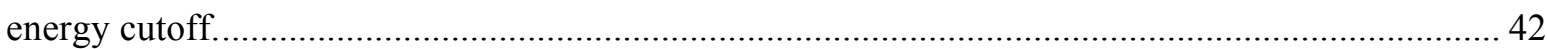

Table 10.2. Model compared to experiment efficiency as a function of boron lining material................. 43 


\section{Introduction}

The Department of Energy Office of Nuclear Safeguards (NA-241) is supporting the project "Coincidence Counting With Boron-Based Alternative Neutron Detection Technology" at Pacific Northwest National Laboratory (PNNL) for development of an alternative neutron coincidence counter [Kouzes 2012; Siciliano 2012].

The development of coincidence counters based on boron-lined proportional counters requires that models be developed to simulate the performance of the systems. The models are necessary to optimize the system design and to predict if adequate performance can be realized. In order to have confidence in the models of the complete coincidence counter designs, it is important to create models of simple systems that can be compared to experimental measurements.

This paper reports the model results of boron-lined proportional counter systems and the experimental measurements performed to validate the calculation methods used in those models, i.e., shows whether the model accurately represents the experimental measurements. The strategy for this project is to use the model parameters that provide the best comparison to the measured total count rates, which may or may not be related to the key unknown component of the models: the actual material composition or thickness of the lining. No information from the vendor on the actual boron coating was used in this study. Although examples of measured pulse-height spectra are also given here, agreement between modeled and measured pulse-heights is not used in this report as a measure of modeling accuracy because the shapes of the calculated spectra depend upon the same unknown proprietary details of the boron lining and the proportional gas. A future report will focus on comparison of pulse height spectra and their dependences on the boron lining and proportional gas.

For this validation work, two systems were tested and modeled. Both used boron-lined proportional counter tubes manufactured by General Electric (GE) Reuter-Stokes. The first of these comparisons was performed using simple individual tubes, similar to the one shown schematically in Figure 1.1. Measurements were made with a bare tube and with the tube surrounded by a block of high-density polyethylene (HDPE) to act as a moderator.

The second system modeled and measured was a pre-built Neutron Detection Module (NDM) designed as a "drop-in" replacement unit for the ${ }^{3} \mathrm{He}$-based NDMs currently used in radiation portal monitors. It is produced in quantity by GE Reuter-Stokes, and consists of an array of 20 ${ }^{10}$ B-lined proportional tubes embedded within a larger box (or "panel") filled with HDPE, shown in Figure 1.2. The tubes in this system are similar to, but longer than, the individual tubes mentioned above. The panels provided by GE Reuter-Stokes were from different prototype runs, and thus had some variation in characteristics. 


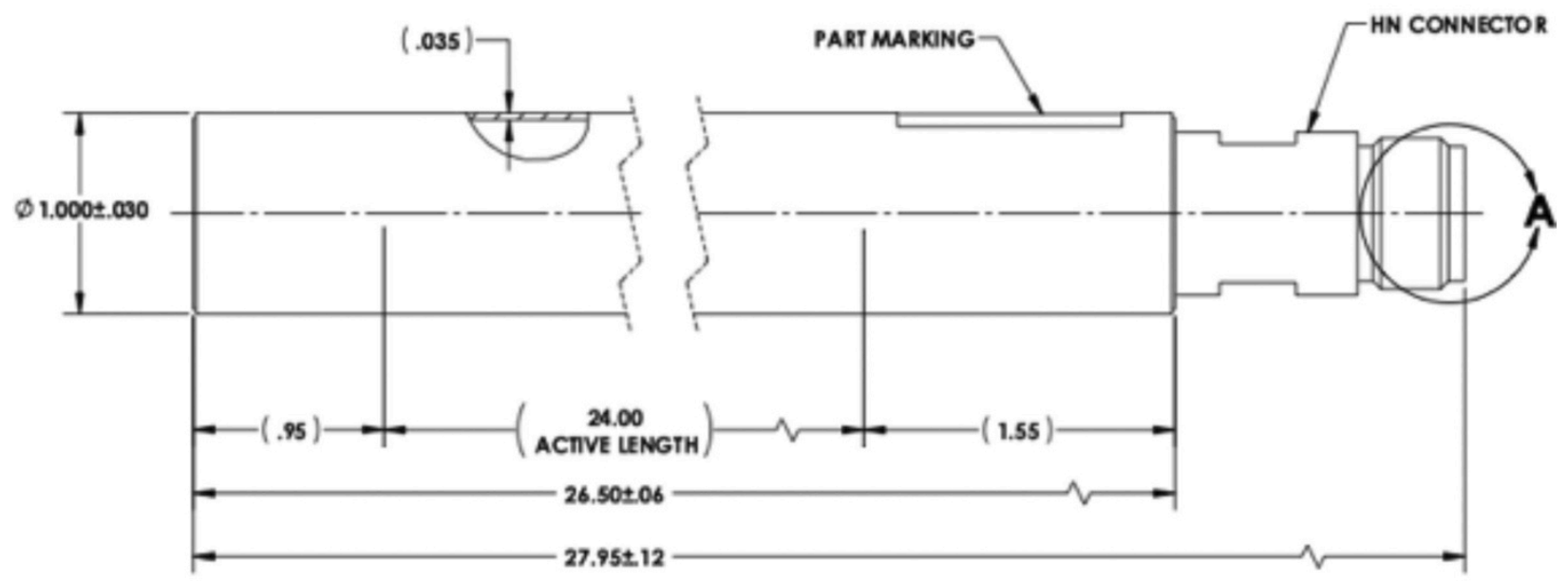

Figure 1.1. Schematic of a GE Reuter Stokes ${ }^{10}$ B-lined proportional counter (units are inches).

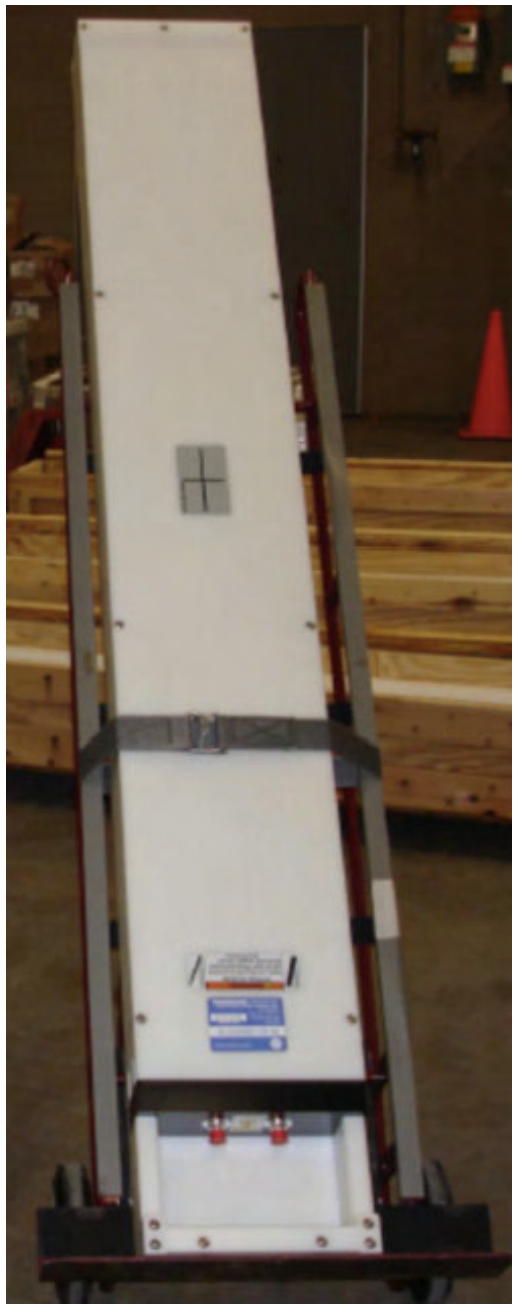

Figure 1.2. GE Reuter Stokes NDM "panel” containing an array of ${ }^{10} B$-lined proportional counters. 


\section{Experimental Measurements}

Measurements were made on two boron-lined tube systems: simple individual tubes and a more complex multi-tube array contained within a pre-built NDM panel.

\subsection{Individual Tube Measurements}

Two $71.1 \mathrm{~cm}$ (28-inch) long boron-lined tubes (GE Reuter Stokes model 0824-101) were individually measured for their response to a bare and moderated ${ }^{252} \mathrm{Cf}$ neutron source $(11.75$ $\mu \mathrm{Ci}[21.8 \mathrm{ng}]$ on the date of the first measurements). The tubes had serial numbers of Tube 1: $11 \mathrm{~K} 00 \mathrm{LKG}$ and Tube 2: 11K00LKH.

Measurements were made on February 17, 2012, with the bare boron-lined tubes. Figure 2.1 shows the bare boron-lined tube mounted horizontally on a tripod $1.77 \mathrm{~m}$ off the floor in the high bay of Building 3440 at PNNL. Although other structures were much farther from the tube than the floor, their background contribution to these measurements may not be negligible. The high voltage on the tubes was set at $760 \mathrm{~V}$, consistent with information provided by the vendor. A shaping time of $1 \mu \mathrm{s}$ was used for these measurements. Measurements were taken for 500-900 s with the source at distances of $0.25,0.50,1.0$, and $2.0 \mathrm{~m}$ from the tube center.

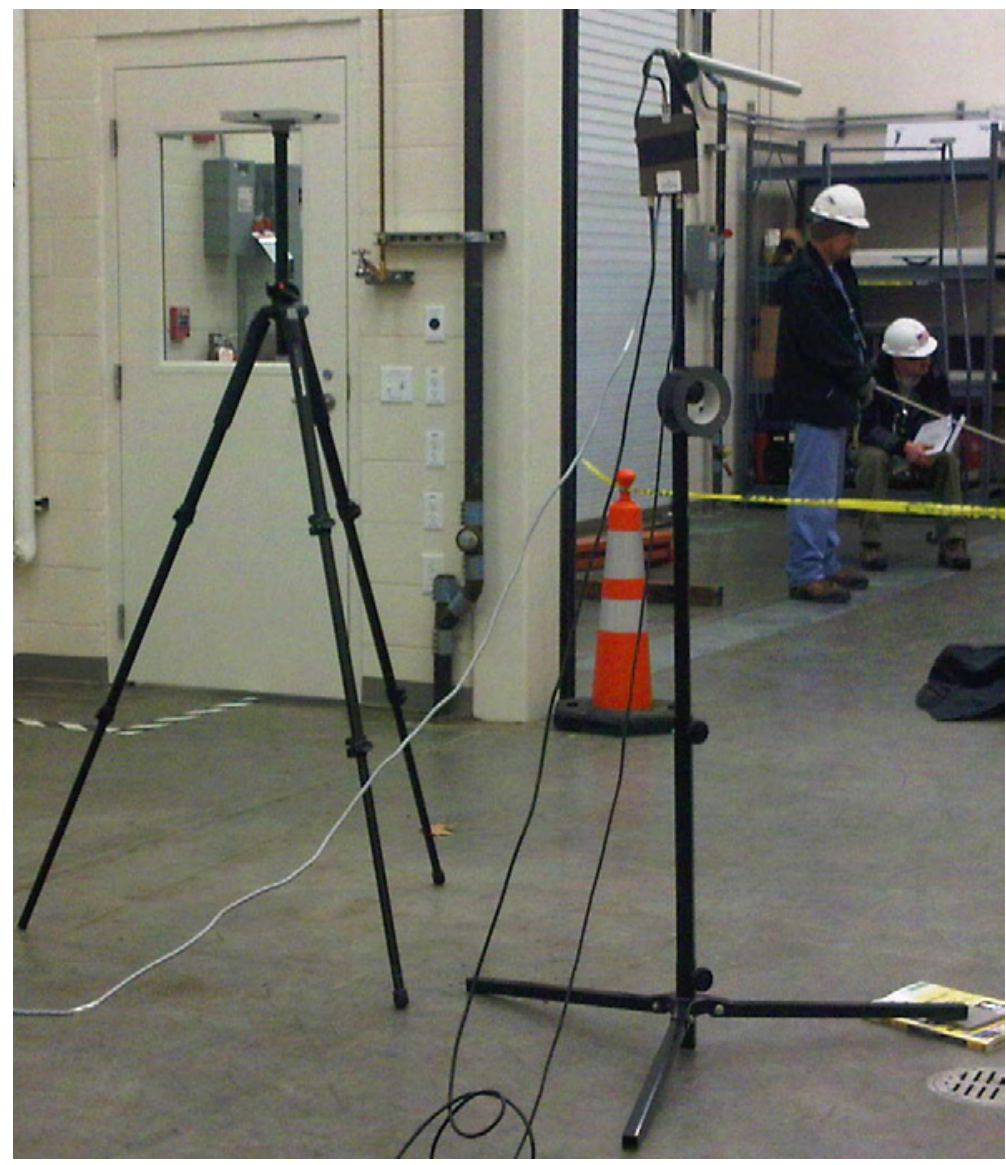

Figure 2.1. Bare boron-lined tube on tripod (right) and source holder (left) in high bay. 
Measurements were made on March 14, 2012, of the boron-lined tubes surrounded by a HDPE moderator box. Figure 2.2 shows the boron-lined tube and moderator centered vertically on a tripod $1.5 \mathrm{~m}$ off the floor in the high bay of Building 3440. The HDPE box had dimensions 10.5 $\mathrm{cm} \times 10.5 \mathrm{~cm} \times 61 \mathrm{~cm}$, with a $2.54 \mathrm{~cm}$ hole bored down the middle into which the tube was inserted. As with the bare tube measurements, all other structures were much farther from the tube than the floor. The high voltage was set at $760 \mathrm{~V}$, consistent with information provided by the vendor. A shaping time of $0.5 \mu$ s was used for these measurements. Measurements were taken for $600 \mathrm{~s}$ at distances of $0.10,0.25,0.50,1.0$, and $2.0 \mathrm{~m}$ from the center of the front face of the HDPE box.

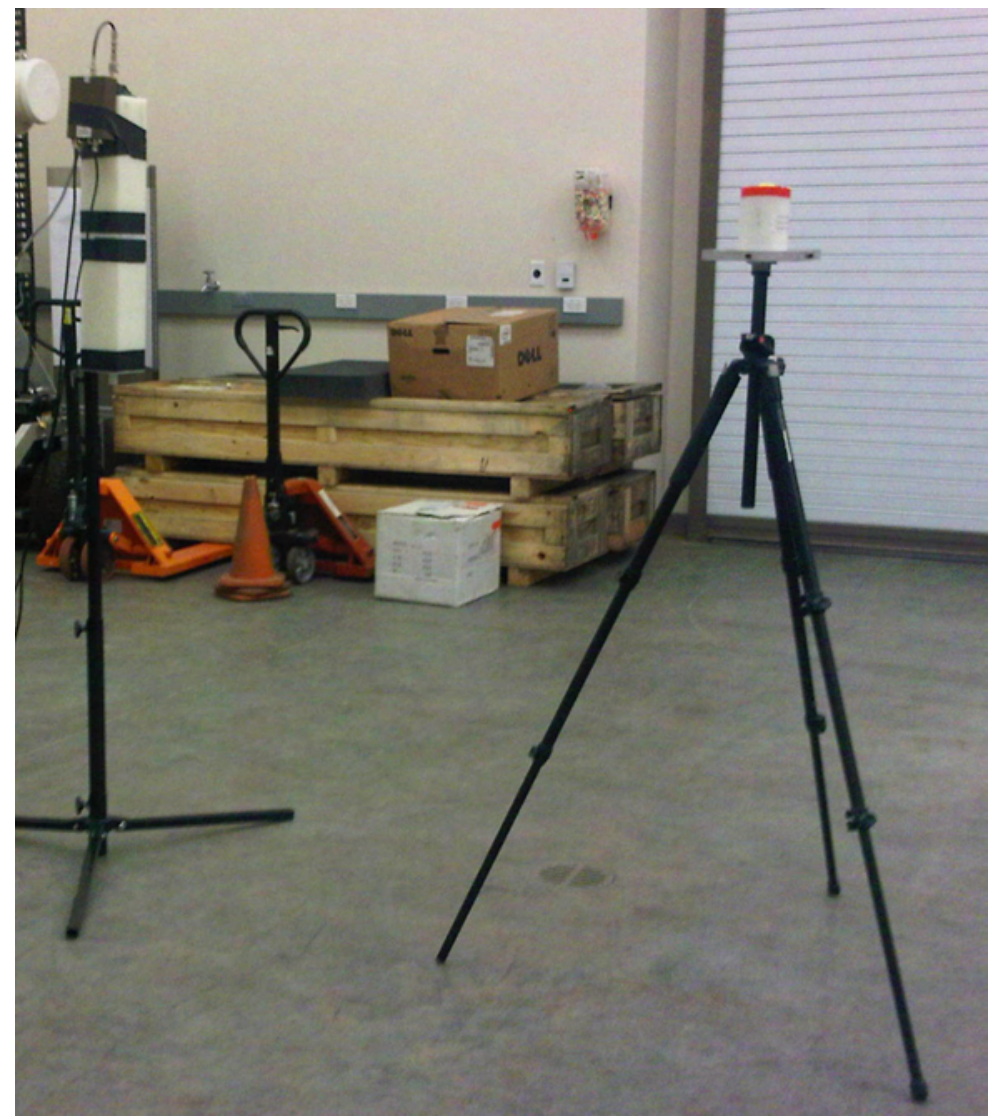

Figure 2.2. Boron-lined tube inside polyethylene on tripod (left) and source holder (right) in high bay.

For both sets of measurements, the ${ }^{252} \mathrm{Cf}$ source was either bare or in a moderating pig (seen in Figure 2.2 on the tripod) consisting of $0.64 \mathrm{~cm}$ lead surrounded by $2.54 \mathrm{~cm}$ of HDPE. Figure 2.3 shows the net (background subtracted) response of bare Tube 2 to a moderated ${ }^{252} \mathrm{Cf}$ neutron source at $25 \mathrm{~cm}$ after $500 \mathrm{~s}$. Figure 2.4 shows the net response of moderated Tube 2 to a moderated ${ }^{252} \mathrm{Cf}$ neutron source at $25 \mathrm{~cm}$ after $500 \mathrm{~s}$. Note that the horizontal gain was somewhat different for these two sets of measurements (due to different electronics settings being used). Moderating the tube produces many more counts but does not change the shape of the observed pulse-height spectrum of the tube, shown below in Figures 2.3 and 2.4. 


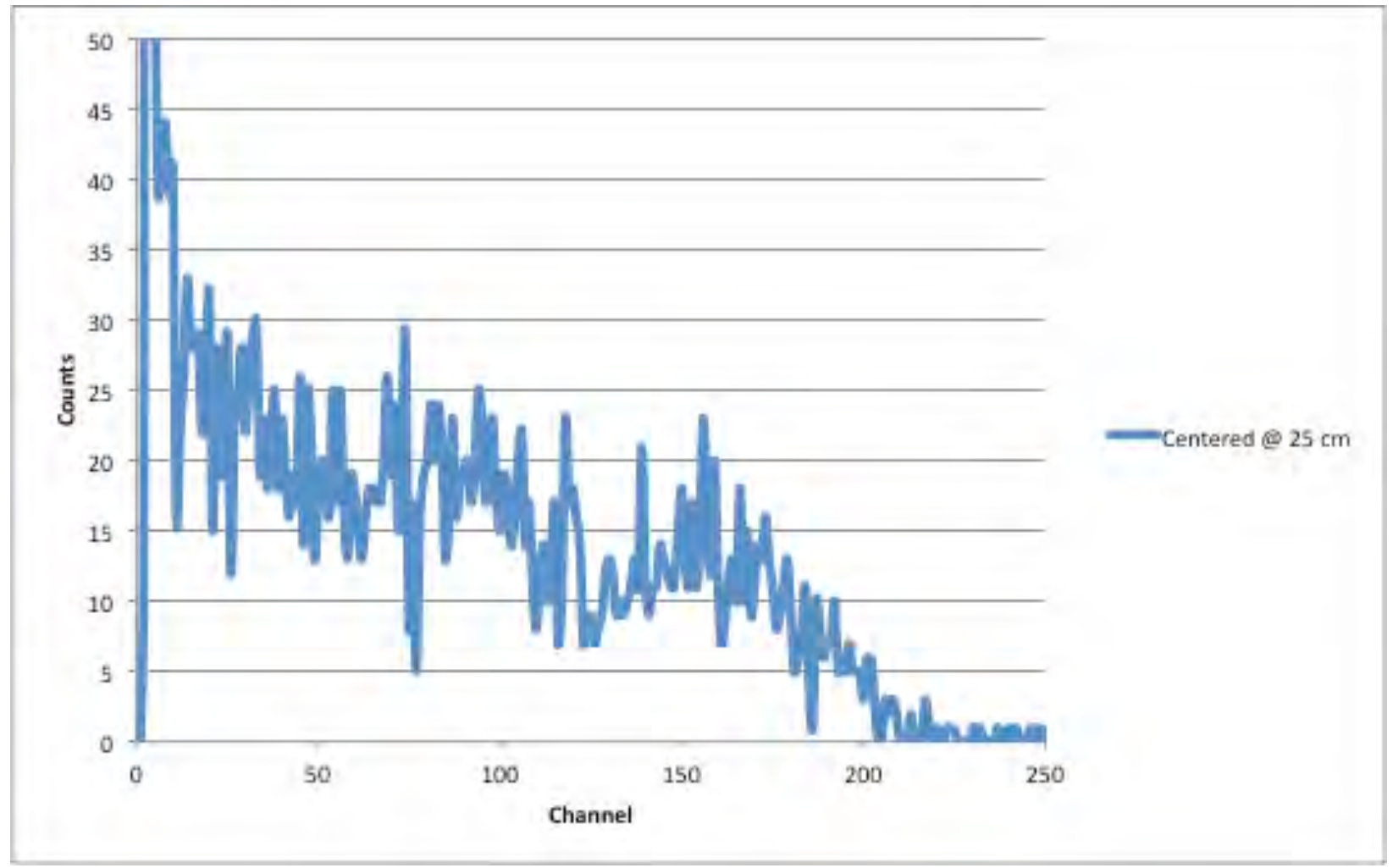

Figure 2.3. Net bare boron-lined Tube 2 response $25 \mathrm{~cm}$ from the source acquired for $500 \mathrm{~s}$.

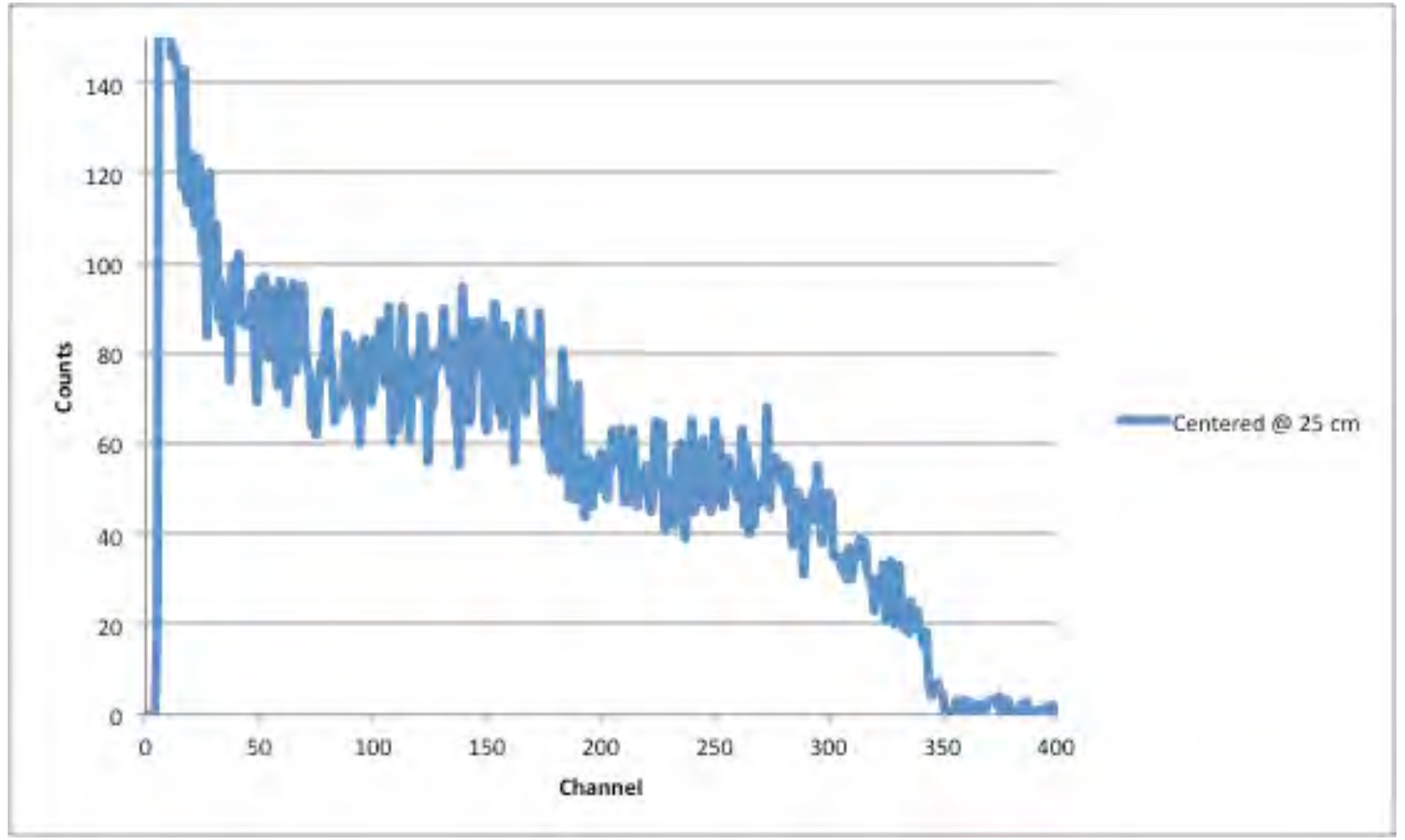

Figure 2.4. Net moderated boron-lined Tube 2 response $25 \mathrm{~cm}$ from the source acquired for $500 \mathrm{~s}$. 
Table 2.1 shows some of the measured total counts per second (cps) rates taken for both bare and moderated configurations at the same source distances. The first four rows show the results for Tubes 1 and 2 with no moderator around the detector, at a distance of $25 \mathrm{~cm}$ from the source (bare or moderated). For these entries, the net cps/ng are shown above an analysis threshold at channel $7(\sim 50 \mathrm{keV})$. The uncertainty shown is only from statistics, and other systematic uncertainties like positioning errors and source strength are assumed to be a few percent. The response of the bare tubes to the bare source is very low, as might be expected, and probably largely represents the response to neutrons moderated by the floor of the high bay (and to a smaller degree, the rest of the room). The response to the moderated source is significantly larger.

The second set of four rows in the table show the results for Tubes 1 and 2 with the moderator around the detector, at a distance of $25 \mathrm{~cm}$ from the source (bare or moderated). The third set of four rows in the table show the results for Tubes 1 and 2 with the moderator around the detector, at a distance of $50 \mathrm{~cm}$ from the source (bare or moderated). For the moderated tube entries, the net cps/ng are shown above a threshold at channel $12(\sim 50 \mathrm{keV})$, approximately an equal position in the energy spectrum as that used for the bare tube measurements. Comparing the results at $25 \mathrm{~cm}$, the moderated tubes have a much larger response than the bare tubes, and are largely independent of whether the source is moderated or not. For reference, the complete set of moderated single-tube measurements at different distances and cut-off thresholds are listed in the Appendix.

Table 2.1. Results from individual tube measurements

\begin{tabular}{||l|l|l|l|l||}
\hline \hline Detector & \multicolumn{1}{|c|}{ Moderator } & \multicolumn{1}{|c|}{ Source } & \multicolumn{1}{c|}{ Distance } & \multicolumn{1}{c|}{ cps/ng } \\
\hline Tube 1 & None & Bare & $25 \mathrm{~cm}$ & $0.004 \pm 0.001$ \\
\hline Tube 1 & None & Moderated & $25 \mathrm{~cm}$ & $0.263 \pm 0.005$ \\
\hline Tube 2 & None & Bare & $25 \mathrm{~cm}$ & $0.001 \pm 0.002$ \\
\hline Tube 2 & None & Moderated & $25 \mathrm{~cm}$ & $0.293 \pm 0.005$ \\
\hline \multicolumn{5}{|l}{} \\
\hline Tube 1 & $10.5 \times 10.5 \times 62 \mathrm{~cm}^{3}$ & Bare & $25 \mathrm{~cm}$ & $1.61 \pm 0.01$ \\
\hline Tube 1 & $10.5 \times 10.5 \times 62 \mathrm{~cm}^{3}$ & Moderated & $25 \mathrm{~cm}$ & $1.64 \pm 0.01$ \\
\hline Tube 2 & $10.5 \times 10.5 \times 62 \mathrm{~cm}^{3}$ & Bare & $25 \mathrm{~cm}$ & $1.68 \pm 0.01$ \\
\hline Tube 2 & $10.5 \times 10.5 \times 62 \mathrm{~cm}^{3}$ & Moderated & $25 \mathrm{~cm}$ & $1.64 \pm 0.01$ \\
\hline \multicolumn{5}{|l|}{} \\
\hline Tube 1 & $10.5 \times 10.5 \times 62 \mathrm{~cm}^{3}$ & Bare & $50 \mathrm{~cm}$ & $0.597 \pm 0.007$ \\
\hline Tube 1 & $10.5 \times 10.5 \times 62 \mathrm{~cm}^{3}$ & Moderated & $50 \mathrm{~cm}$ & $0.632 \pm 0.007$ \\
\hline Tube 2 & $10.5 \times 10.5 \times 62 \mathrm{~cm}^{3}$ & Bare & $50 \mathrm{~cm}$ & $0.622 \pm 0.007$ \\
\hline Tube 2 & $10.5 \times 10.5 \times 62 \mathrm{~cm}^{3}$ & Moderated & $50 \mathrm{~cm}$ & $0.658 \pm 0.007$ \\
\hline
\end{tabular}

\subsection{Multi-Tube Panel Measurements}

Four similar GE Reuter Stokes NDM "panels" with arrays of boron-lined tubes were individually measured for their response to a bare and moderated ${ }^{252} \mathrm{Cf}$ neutron source $(11.75 \mu \mathrm{Ci}$ [21.8 ng] on the date of the measurements of February 17, 2012). These panels (serial numbers 10HBN228, 10HBN229, 10HBN281, 11E004JA), such as the one seen in Figure 2.5, are 
designed as replacement modules for radiation portal monitors. The panels provided by GE Reuter-Stokes were from different prototype runs, and thus had some variation in characteristics. The outer dimensions of these panels are $0.13 \mathrm{~m}$ x $0.30 \mathrm{~m} \times 1.91 \mathrm{~m}$, and they contain $202.54-\mathrm{cm}$ diameter (1.79 $\mathrm{m}$ active length) boron-lined tubes arranged in 3 rows. The panel was mounted horizontally, centered $1.5 \mathrm{~m}$ above the floor.

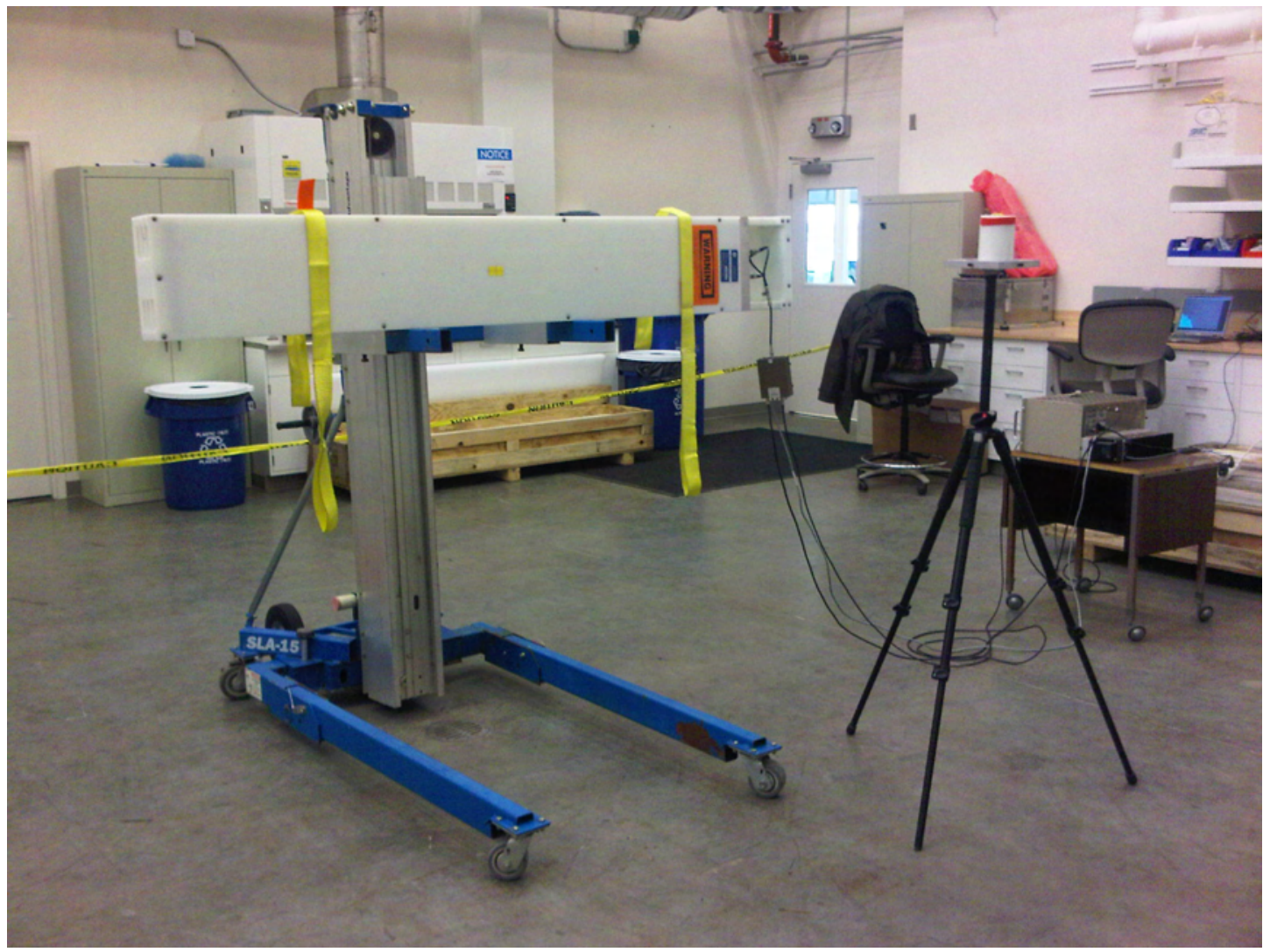

Figure 2.5. Panel containing of boron-lined tubes on lift (right) and source holder (left) in high bay.

Measurements were made on the front of the panel for source positions $100 \mathrm{~cm}$ from the face of the panel at the center and at both ends, and at $200 \mathrm{~cm}$ from the center. Measurements were also made at $100 \mathrm{~cm}$ from the center of the back of the panel. All measurements were made for $300 \mathrm{~s}$, except the background was measured for $1800 \mathrm{~s}$. All detectors were operated at $800 \mathrm{~V}$. A shaping time of $0.5 \mu \mathrm{s}$ was used for these measurements. Figure 2.6 shows the net pulse-height energy spectrum from panel 10HBN281 taken with the center of the source at $15 \mathrm{~cm}$ from the center face of the panel. It is similar to that from a single tube, but is the sum of 20 tubes all operating at the same voltage.

Table 2.2 shows some of the results from the measurements, using a threshold at $\sim 50 \mathrm{keV}$ (channel 7 for the first three panels, and channel 9 for the fourth since it had different gain characteristics) to find the sum of counts. Uncertainties in values are several percent. The four panels are seen to be similar in performance within a few percent. The absolute efficiency at $2 \mathrm{~m}$ is seen to be about $3 \mathrm{cps} / \mathrm{ng}$ for each of the units. This exceeds the specification for absolute efficiency required of neutron detection units used in radiation portal monitors (for which application this NDM panel was designed) of at least $2.5 \mathrm{cps} / \mathrm{ng}$ at $2 \mathrm{~m}$. 


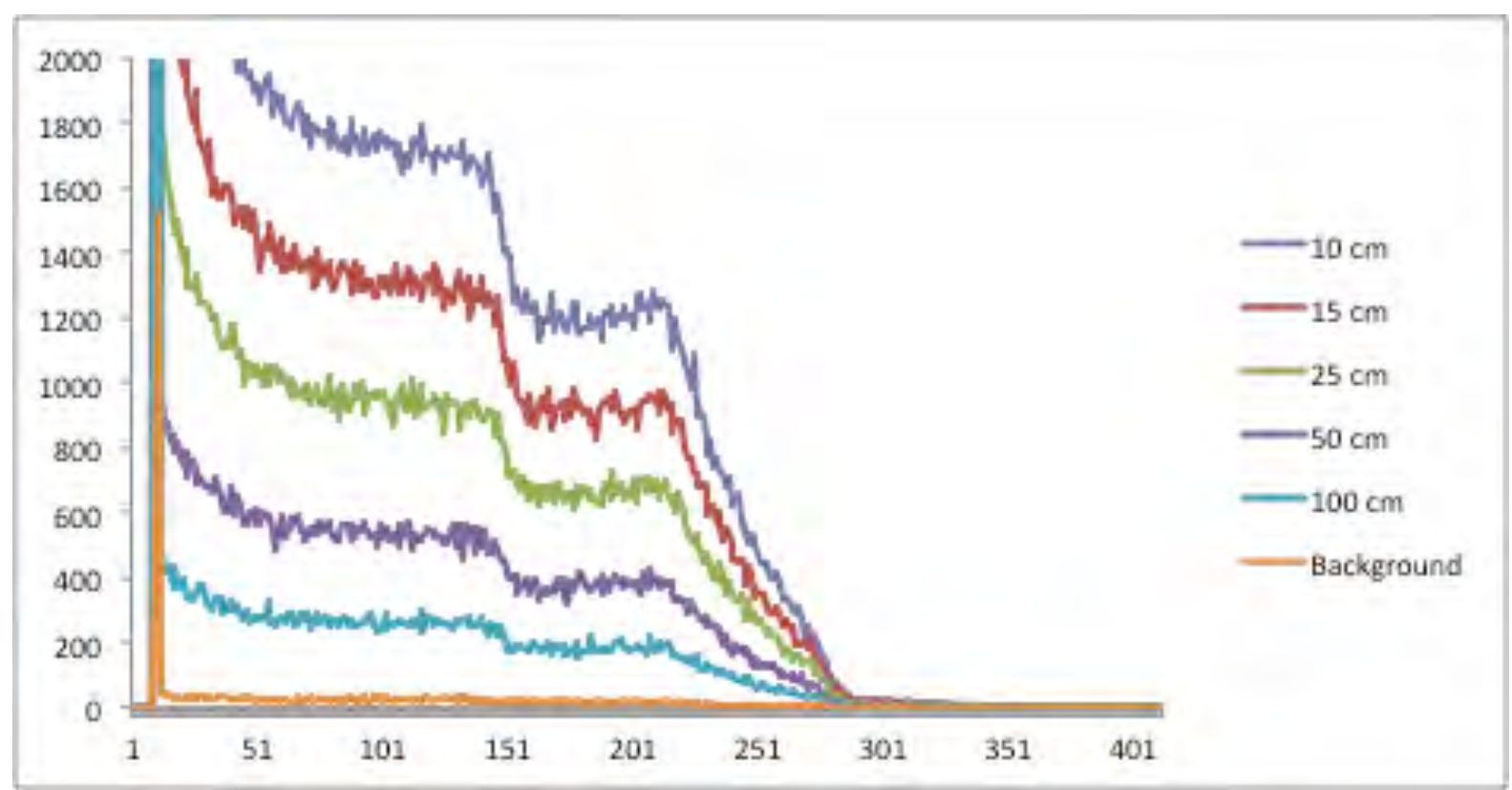

Figure 2.6. Pulse-height spectra from panel 10HBN281 with source at various distances.

Table 2.2. Results from multi-tube panel measurements.

\begin{tabular}{|c|c|c|c|}
\hline Detector & Orientation & Distance & cps/ng \\
\hline 10HBN228 & Front Top & $1 \mathrm{~m}$ & $5.16 \pm 0.028$ \\
\hline 10HBN229 & Front Top & $1 \mathrm{~m}$ & $5.15 \pm 0.028$ \\
\hline $10 \mathrm{HBN} 281$ & Front Top & $1 \mathrm{~m}$ & $5.31 \pm 0.028$ \\
\hline $11 \mathrm{E} 004 \mathrm{JA}$ & Front Top & $1 \mathrm{~m}$ & $5.21 \pm 0.028$ \\
\hline 10HBN228 & Front Center & $1 \mathrm{~m}$ & $8.01 \pm 0.035$ \\
\hline 10HBN229 & Front Center & $1 \mathrm{~m}$ & $8.08 \pm 0.035$ \\
\hline 10HBN281 & Front Center & $1 \mathrm{~m}$ & $8.45 \pm 0.036$ \\
\hline 11E004JA & Front Center & $1 \mathrm{~m}$ & $8.05 \pm 0.035$ \\
\hline 10HBN228 & Front Bottom & $1 \mathrm{~m}$ & $5.31 \pm 0.028$ \\
\hline 10HBN229 & Front Bottom & $1 \mathrm{~m}$ & $5.45 \pm 0.029$ \\
\hline 10HBN281 & Front Bottom & $1 \mathrm{~m}$ & $5.68 \pm 0.029$ \\
\hline 11E004JA & Front Bottom & $1 \mathrm{~m}$ & $5.35 \pm 0.029$ \\
\hline 10HBN228 & Back Center & $1 \mathrm{~m}$ & $7.33 \pm 0.033$ \\
\hline 10HBN229 & Back Center & $1 \mathrm{~m}$ & $7.7 \pm 0.034$ \\
\hline $10 \mathrm{HBN} 281$ & Back Center & $1 \mathrm{~m}$ & $7.6 \pm 0.034$ \\
\hline 11E004JA & Back Center & $1 \mathrm{~m}$ & not measured \\
\hline 10HBN228 & Front Center & $2 \mathrm{~m}$ & $2.88 \pm 0.021$ \\
\hline 10HBN229 & Front Center & $2 \mathrm{~m}$ & $3.08 \pm 0.022$ \\
\hline 10HBN281 & Front Center & $2 \mathrm{~m}$ & $3.1 \pm 0.022$ \\
\hline 11E004JA & Front Center & $2 \mathrm{~m}$ & $2.99 \pm 0.021$ \\
\hline
\end{tabular}




\subsection{Measurements with an Assembly of Four Multi-Tube Panels}

The same four NDM panels of boron-lined tubes were measured as an assembly in a square configuration to determine their response to a moderated ${ }^{252} \mathrm{Cf}$ neutron source $(11.37 \mu \mathrm{Ci}$ [ 21.1 ng or $44217 \mathrm{n} / \mathrm{s}$ ] on the April 2, 2012). These four panels (serial numbers 10HBN228, $10 \mathrm{HBN} 229,10 \mathrm{HBN} 281,11 \mathrm{E} 004 \mathrm{JA}$ ) were put into this close packed square configuration with inner dimension $25.4 \mathrm{~cm} \times 30.5 \mathrm{~cm}$ to approximate a typical, albeit large, configuration used for coincidence counters. The panels were set vertically on the floor with the bottom of the source positioned $94.6 \mathrm{~cm}$ above the floor (that being the position of the tube centers within the panel). Figure 2.7 shows the source located within three of the panels, while Figure 2.8 shows the completed assembly of four panels.

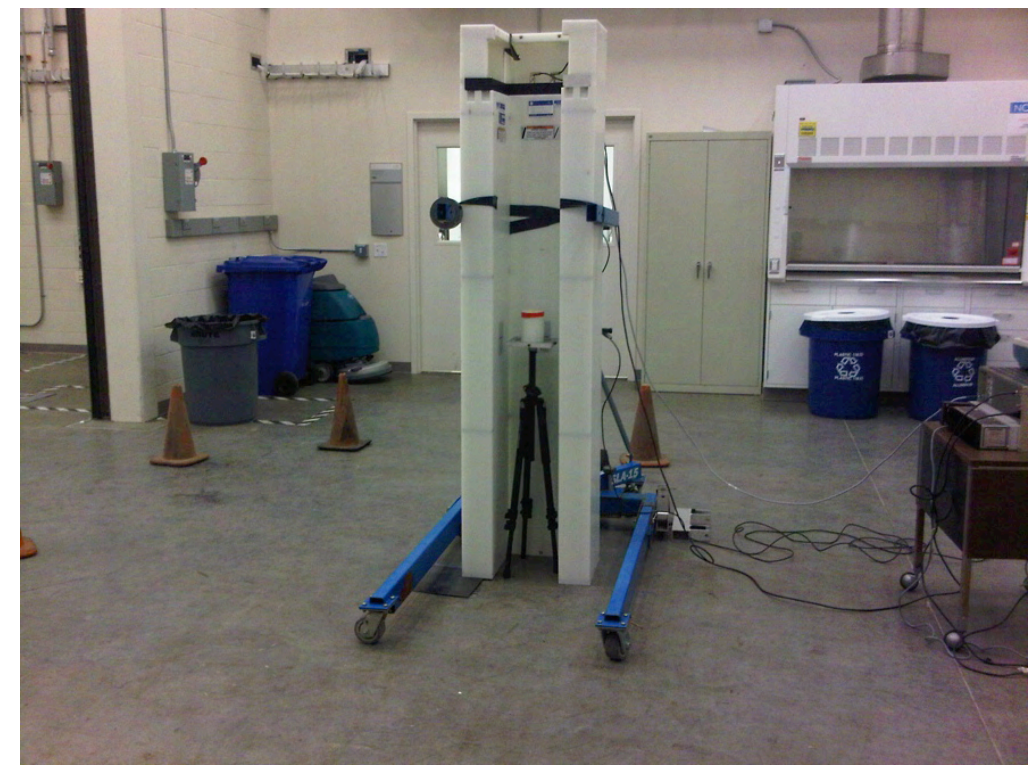

Figure 2.7. Three boron-lined tube panels on floor of the high bay.

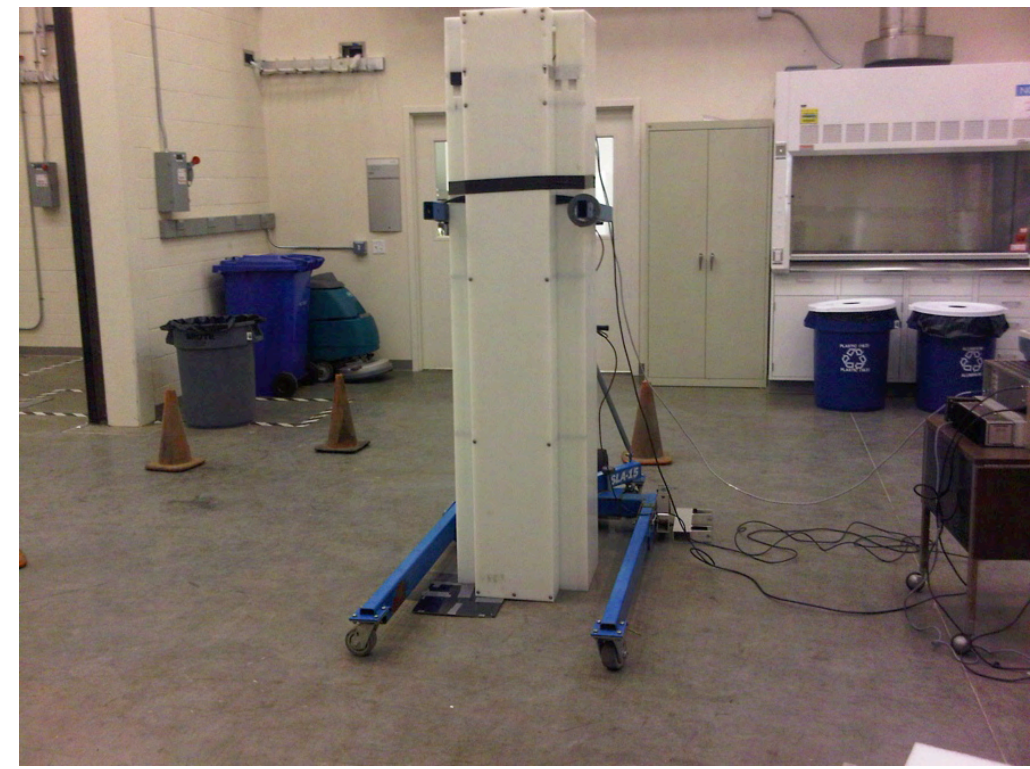

Figure 2.8. Four-panel configuration on floor of the high bay. 
Measurements were made on each of the four panels individually using the same preamplifier, amplifier and high voltage $(760 \mathrm{~V})$. Figure 2.9 shows the results of the measurements on one of the panels in the three-panel assembly and for each of the panels in the four-panel assembly. Panels were numbered clockwise from above starting at the one farthest away in the photograph. The gain and efficiency of three of the panels in the four-panel assembly are similar, but the fourth panel has higher gain, indicating it has a somewhat different anode wire size or gas pressure.

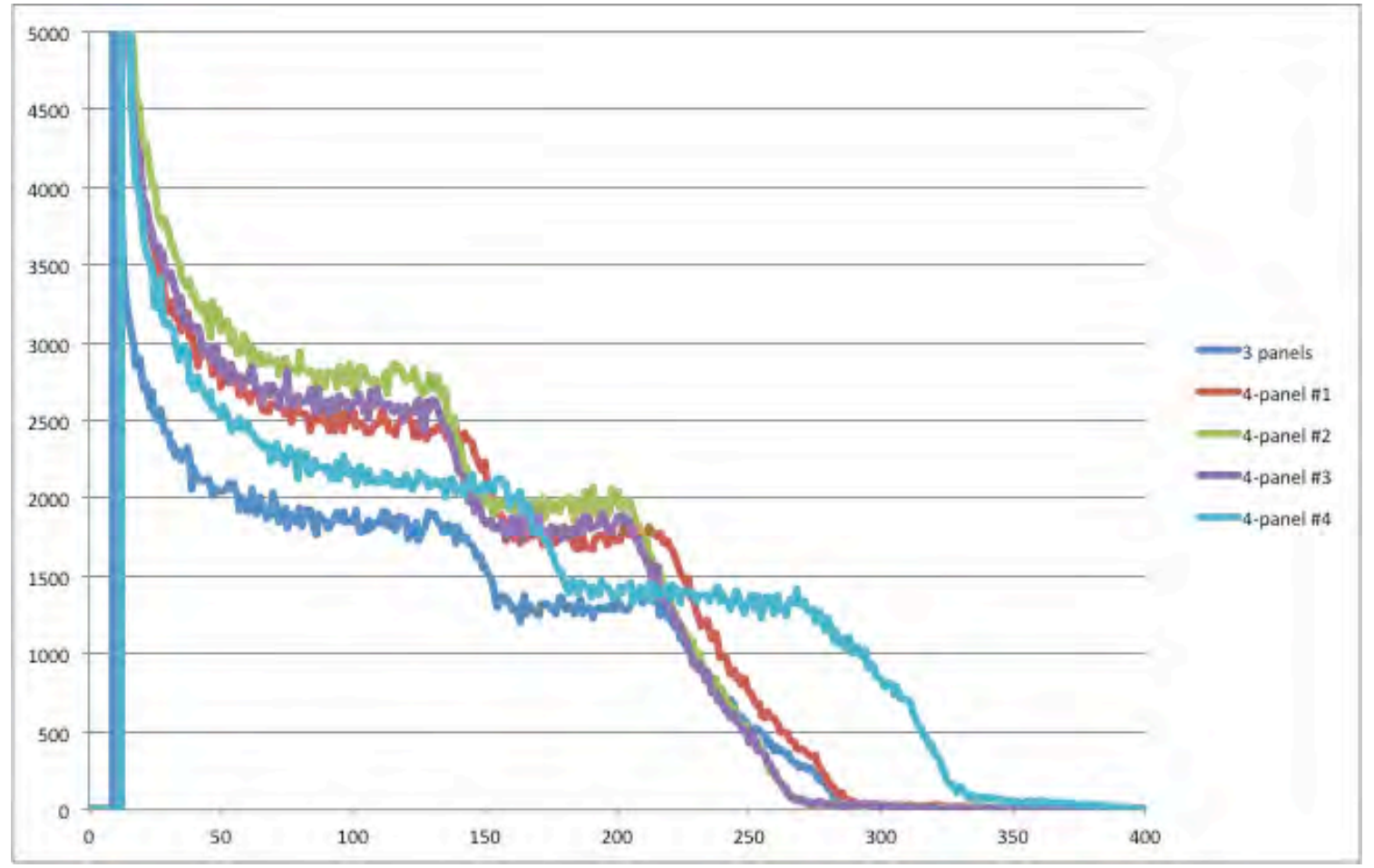

Figure 2.9. Pulse-height responses of the four-panel Assembly.

Table 2.3 shows the count rates per nanogram for the four panels in the square assembly as a function of three different energy thresholds. The assembly thus had a total efficiency (counts/neutron emitted) of 14.8\% - 15.9\% depending on the threshold used. An MCNPX model of this assembly was developed, and over predicted the response of the assembly by $\sim 18 \%$ when using the default parameters of a $0.75 \mu \mathrm{m}$ boron metal lining. Further refinement of the model would likely improve agreement, but this is not part of the current project plan.

Table 2.3. Results from the four-panel Assembly measurements.

\begin{tabular}{||c|r|r|r|r|r|r||}
\hline & Net cps/ng & Model & Net cps/ng & Model & Net cps/ng & Model \\
\hline Panel & $\mathbf{8 0} \mathbf{~ k e V}$ & $\mathbf{> 0 0} \mathbf{~ k e V}$ & $>\mathbf{1 0 0} \mathbf{~ k V}$ & $>\mathbf{1 0 0} \mathbf{~ k e V}$ & $>\mathbf{1 2 0} \mathbf{~ k e V}$ & $>\mathbf{1 2 0} \mathbf{~ k e V}$ \\
\hline$\# \mathbf{1}$ & 83 & & 80 & & 77 & \\
\hline$\# \mathbf{2}$ & 87 & & 83 & & 80 & \\
\hline$\# \mathbf{3}$ & 81 & & 78 & & 75 & \\
\hline$\# \mathbf{4}$ & 84 & & 81 & & 78 & \\
\hline Total & 334 & & 322 & & 310 & \\
\hline Efficiency & $15.9 \%$ & $18.3 \%$ & $15.3 \%$ & $18.1 \%$ & $14.8 \%$ & $17.8 \%$ \\
\hline
\end{tabular}




\section{Model Comparison for Individual Tubes}

Simulation has been used to vary designs, configurations, and parameters for coincidence and multiplicity detectors to optimize the neutron detection capability of the systems through techniques built on previous experience [Lintereur 2010]. A modeling study has been performed at PNNL on some multiplicity counter implementations of ${ }^{3} \mathrm{He}$ alternative neutron detectors [Ely 2011; 2011b]. The Extended, Monte Carlo N-Particle (MCNPX, version 2.70) radiation transport code [MCNPX 2011] was used for the models discussed here. The model took into account the entire environment for the measurement, including the floor, walls, electronics, source tripod and detector support, as seen in Figure 3.1.

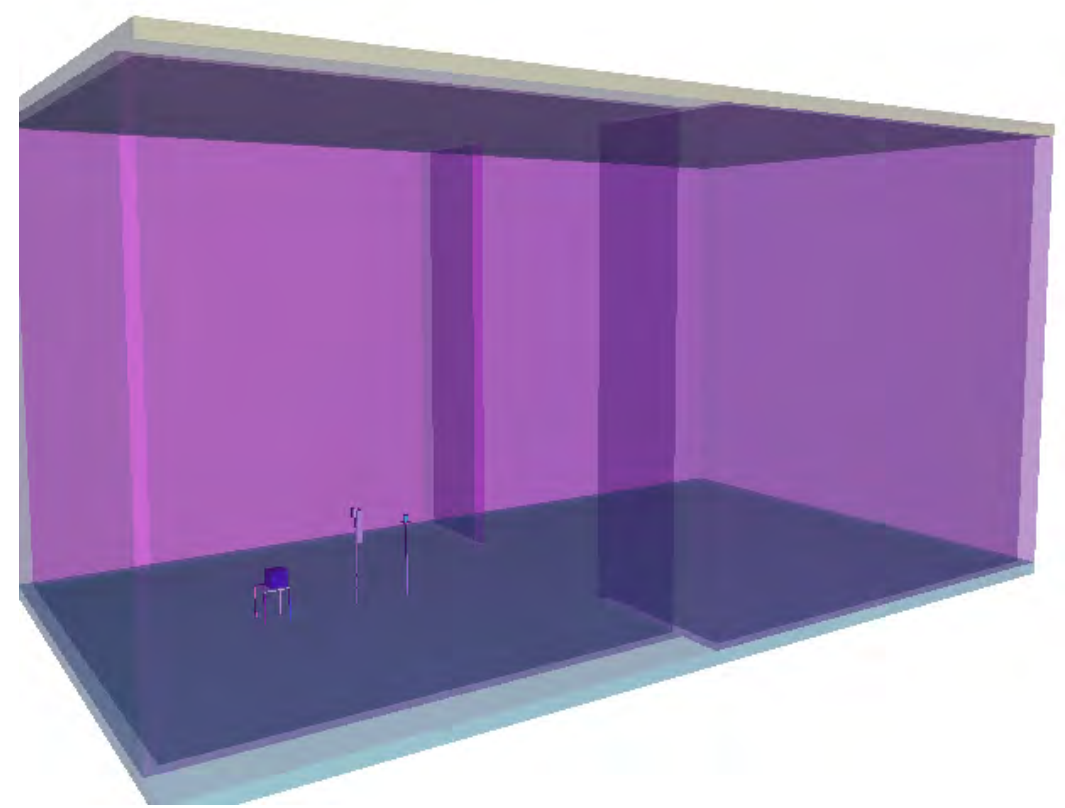

Figure 3.1. 3-D view of the High Bay.

Figure 3.2 shows details of the moderated source model. The moderated source consists of ${ }^{252} \mathrm{Cf}$ inside a steel capsule, placed in a lead lined polyethylene moderator set on an aluminum plate on a tripod. It consists of three concentric cylinders with the smallest being an air-filled source compartment $7.62 \mathrm{~cm}$ high and $2.54 \mathrm{~cm}$ diameter. The next is a $6.35 \mathrm{~mm}$ thick lead liner, $8.9 \mathrm{~cm}$ high and $3.81 \mathrm{~cm}$ in diameter, which attenuates the photons emitted by the ${ }^{252} \mathrm{Cf}$ source. The outer cylinder is a $2.54 \mathrm{~cm}$ thick HDPE shell, $14 \mathrm{~cm}$ high, which moderates the neutrons emitted from the ${ }^{252} \mathrm{Cf}$ source. Typical model runs involved transport of $10^{6}$ neutrons emitted from the source. For all models, a $96 \%$ enrichment of ${ }^{10} \mathrm{~B}$ was used for the boron in the detector. The tubes were assumed to have one atmosphere pressure; it is now know that the pressure is closer to one third of an atmosphere. Thus, the individual tube results presented here will tend to overestimate response by a few percent.

The models are very complete with respect to the surrounding environment. Figure 3.3 provides a view of a number of neutron tracks transported in the model. Tracks that left the room walls were truncated (a few tracks through the floor are shown). 


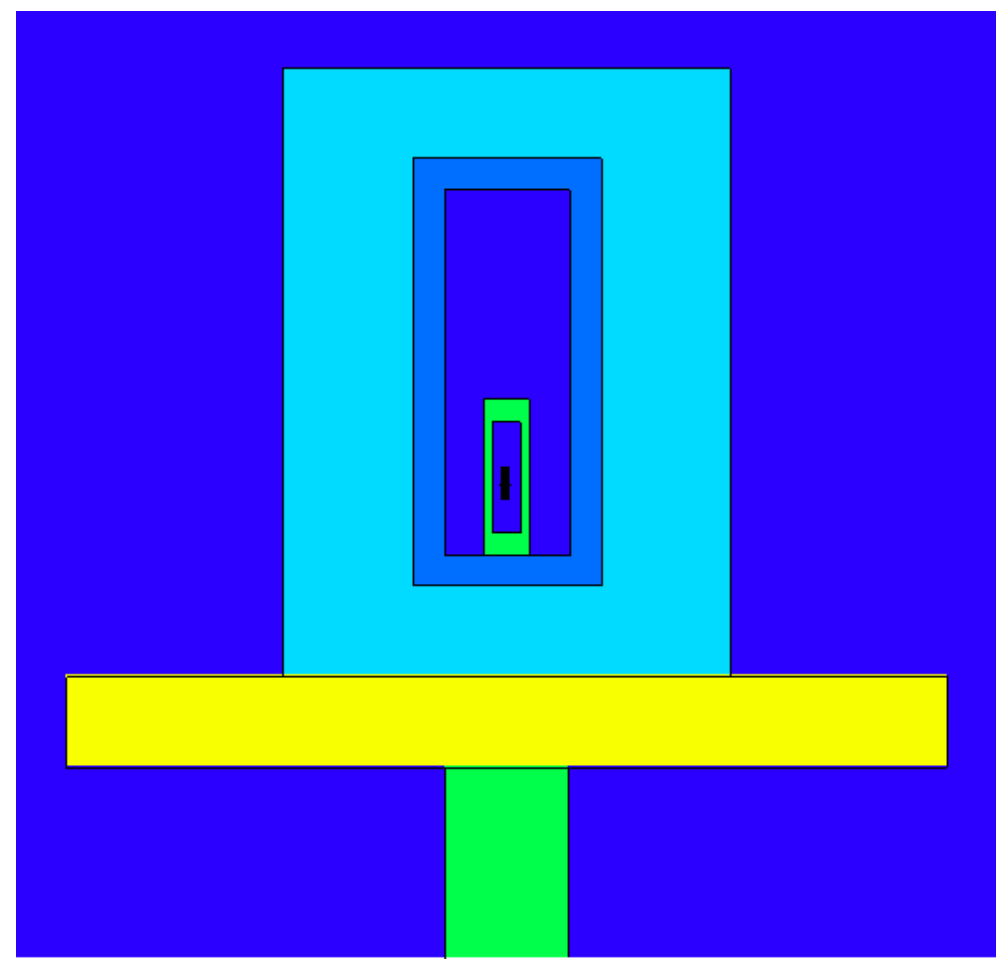

Figure 3.2. Schematic of source in the pig [source is the black cylinder inside the steel (green) case].

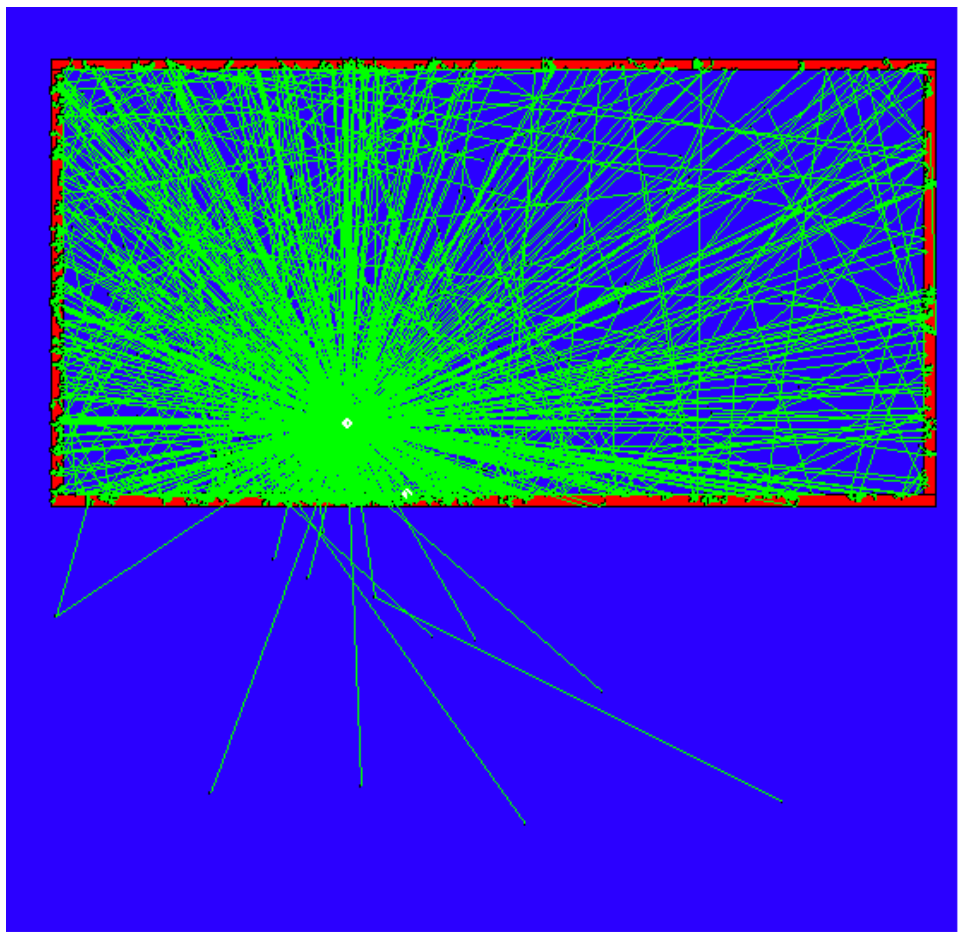

Figure 3.3. Neutron tracks in the room. 


\subsection{Model Evaluation Method}

The simulations of tubes were performed using MCNPX with models based upon design information provided by GE Reuter Stokes. As with any model of real systems, some approximations are required in the geometric accuracy or material compositions of key detection components. For modeling boron-lined systems, like single tubes, those key factors are the composition and average thickness of the boron lining, which are proprietary to the vendor. Another key factor that would affect comparison of the simulated results to measured data was the low-energy cutoff (LEC) value used as the threshold for separating the gamma ray interference region of the spectra from the one used for the neutron count rates. Several different LEC values were modeled and measured. Variations in these key parameters were evaluated to access the overall uncertainty they might introduce when comparing the model results to the measured data.

For boron-lined tubes, it is necessary not only to model the neutron capture, but also the resulting two decay particles since the observed signal results from their interaction in the gas of the proportional counter. There are a number of different MCNPX tally methods that can be used to simulate the response in the proportional gas to neutrons capture reactions taking place in the boron lining [Siciliano 2010; Ely 2011]. All methods require using an MCNPX execution mode that explicitly tracks both the alpha and lithium reaction products, and using the physics options to ensure the trajectories of these two products are anti-correlated so only one per capture is headed towards the center of the tube. This is accomplished by using the neutron capture ion algorithm (NCIA) option. When using this option, it is also advisable to select the neutron physics option value ( $\mathrm{recl}=5$ ) that implements the NCIA whether or not the cross section data includes data for the final state particles. Otherwise any correlation between the two particles is lost if there are data for one light ion in the cross section library being used.

If used correctly, the different methods can be shown to give the same result when the same parameter is evaluated, such as the total count rates. However, not all methods are meant to simulate the spectral shapes of the actual pulse-heights being measured. Because total count rates and pulse-height spectra were an objective for this study, the simplest method that provided both of those results was used. That method is the simple or "original" pulse-height method (tally type F8). The original intent of the F8 tally (algorithm) was to simulate the energy deposition in a detector that resulted from photons or charged particles. Thus it is also applicable to the boronlined case, provided the kinematic constraints of the reaction are imposed by using the NCIA option and a non-conflicting cross section library so that each capture event causes at most one pulse. Note that use of the simple pulse-height algorithm is not valid for the ${ }^{3} \mathrm{He}$ or $\mathrm{BF}_{3}$ cases where only neutron capture is modeled.

The Gaussian energy broadening (GEB) tally treatment was applied to the F8-type tallies used to obtain the results reported here. The GEB treatment is provided to better simulate a physical detector in which energy peaks show Gaussian broadening. Typical use of this option has been for approximating the finite resolution in gamma ray spectroscopy, where once its parameters are adjusted, the resulting pulse-height spectra very closely match measured spectra from physical systems. The GEB tally treatment cannot shift the KE position or change the total count (area) from the pulse-height spectra. Its effect on the simulations reported here is only to smooth the abrupt fall-off that would occur in regions of energy where the alpha and ${ }^{7} \mathrm{Li}$ products reach the maximum kinetic energies available from the reaction Q-values. 
The GEB parameters specify the full width at half maximum (FWHM) of the observed energy broadening by the formula: $F W H M(E)=a+b \sqrt{\left(E+c E^{2}\right)}$, where $E$ is the energy of the particle, and the units of $a, b$, and $c$ are $\mathrm{MeV}, \mathrm{MeV}^{1 / 2}$, and $1 / \mathrm{MeV}$, respectively. The parameters $(a, b, c)$ used in these simulations had values $0.0,0.15,0.0$, respectively. The effect of this value upon the reaction kinetic energy fall-offs can be estimated by taking the ratio of the $F W H M(E)$ to one of the kinetic energy values. For example, the ${ }^{4} \mathrm{He}$ kinetic energy associated with the ${ }^{7} \mathrm{Li}$ excited state has a kinetic energy of $1.47 \mathrm{MeV}$, and the effect is to spread that drop-off by approximately $6 \%$ to each side.

\subsection{Model Results}

Some of the simulation results, showing the percent differences between the models and the experimental measurements for the moderated boron lined tubes, are summarized in Table 3.1. For reference the complete set of moderated single-tube model results are listed in the Appendix.

The experimental values listed in the table as "Measured Averages" are counts per neutron emitted from the source (scaled up by a factor of $10^{4}$ ). The experimental results from the two tubes had similar response, with Tube 2 having a slightly higher efficiency, so the average is shown. A lower energy cutoff (LEC) of $100 \mathrm{keV}$ was applied to both the experimental and simulated results. Several LEC values were modeled and the experimental data was analyzed for these same values (see data tables in the Appendix). The statistical uncertainty of the simulated reaction product currents entering the proportional gas was less than $10 \%$. The values shown for the models are for boron metal and are the percent difference between model and experiment (a positive value indicates the model value is larger than the experimental value). Model results are shown for various boron thicknesses (pure ${ }^{10} \mathrm{~B}$ ) from 0.5 to $2 \mu \mathrm{m}$, and source to moderator distances of $0.1 \mathrm{~m}$ to $2 \mathrm{~m}$.

The best agreement is seen for the thickness of $0.75 \mu \mathrm{m}$. Agreement between model and experiment is worse at larger distances and this may be due to scattering effects not captured in the model that are more important at larger distances. The model results are sensitive to details of the model including the detector and moderator geometry and room scatter, where the floor has the greatest impact. Measurements at the larger distances (1 and $2 \mathrm{~m}$ ) are most sensitive to the room scatter, while the smaller distances are most sensitive to the detector and moderator geometry. Further modeling was conducted and showed that the walls and floor contributed about the same to the reflected signal at 1 and 2 meters. Higher statistics data were also obtained for comparison. Changing the wall or floor description in the model was found to improve the agreement at $2 \mathrm{~m}$ with the high statistics data to about $6 \%$ (from the $32 \%$ shown in the tables) while retaining good agreement at all other distances. Further work will be reported in future papers on improvements to the building model to provide agreement at all distances. Since the thrust of this work is on coincidence collars where the source to detector geometry is close, there is confidence that the current model for the single tube is adequate as reported here for the next phase of model work on the UNCL detector. 
Table 3.1. Percent differences between models and measurements for moderated individual tubes.

\begin{tabular}{|c|c|c|c|}
\hline \multicolumn{3}{|c|}{$\operatorname{LEC}(\mathrm{MeV})==>$} & \multirow[t]{2}{*}{0.100} \\
\hline $\begin{array}{l}\text { Source } \\
\text { Position }\end{array}$ & \multicolumn{2}{|l|}{ Lining Thickness $(\mu \mathrm{m})$} & \\
\hline \multirow[t]{5}{*}{$2 \mathrm{~m}$} & Measured Average $\left(\mathrm{x10}^{4}\right)$ & $==>$ & 0.264 \\
\hline & 0.50 & & $4 \%$ \\
\hline & 0.75 & & $32 \%$ \\
\hline & 1.00 & & $47 \%$ \\
\hline & 2.00 & & $74 \%$ \\
\hline \multirow[t]{5}{*}{$1 \mathrm{~m}$} & Measured Average $\left(\mathrm{x}^{4} 0^{4}\right)$ & $==>$ & 0.805 \\
\hline & 0.50 & & $-29 \%$ \\
\hline & 0.75 & & $12 \%$ \\
\hline & 1.00 & & $30 \%$ \\
\hline & 2.00 & & $39 \%$ \\
\hline \multirow[t]{5}{*}{$0.5 \mathrm{~m}$} & Measured Average $\left(\times 10^{4}\right)$ & $==>$ & 2.585 \\
\hline & 0.50 & & $-18 \%$ \\
\hline & 0.75 & & $1 \%$ \\
\hline & 1.00 & & $19 \%$ \\
\hline & 2.00 & & $30 \%$ \\
\hline \multirow[t]{5}{*}{$0.25 \mathrm{~m}$} & Measured Average $\left(\mathrm{x}^{4} 0^{4}\right)$ & $==>$ & 6.595 \\
\hline & 0.50 & & $-18 \%$ \\
\hline & 0.75 & & $2 \%$ \\
\hline & 1.00 & & $14 \%$ \\
\hline & 2.00 & & $33 \%$ \\
\hline \multirow[t]{5}{*}{$0.1 \mathrm{~m}$} & Measured Average $\left(\mathrm{x}^{4} 0^{4}\right)$ & $==>$ & 17.08 \\
\hline & 0.50 & & $-22 \%$ \\
\hline & 0.75 & & $0 \%$ \\
\hline & 1.00 & & $15 \%$ \\
\hline & 2.00 & & $25 \%$ \\
\hline
\end{tabular}

The ${ }^{10} \mathrm{~B}$ that is coated on the inside of the tubes may be a compound rather than metal, so an organic constituent was added to the lining composition in the model to represent this. The exact lining composition is not known, as it is proprietary, so nitrogen was chosen to represent the organic component of the lining, in the form of boron nitride. Table 3.2 provides comparison to experiment simulation of an individual boron-lined tube in a polyethylene moderator at a sourceto-moderator distance of $1 \mathrm{~m}$ assuming a boron nitride lining, as discussed in Section 3 . The values in the table for each thickness of the lining in micrometers are the percent difference between model and experiment (model minus experiment divided by experiment). A low energy cutoff (LEC) of $100 \mathrm{keV}$ was used for model and experiment in this table. The Appendix provides a more complete comparison of model results. The first set of rows in Table 3.2 is the boron metal results, the second set of rows is the $\mathrm{BN}$ results, and the third set of rows is the $\mathrm{B}_{4} \mathrm{C}$ result, for comparison. 
Table 3.2. Percent differences between simulations and measurements for the moderated individual tubes with various linings.

\begin{tabular}{|c|c|c|}
\hline \multicolumn{2}{|r|}{ LEC $(\mathrm{MeV})==>$} & \multirow[t]{2}{*}{0.100} \\
\hline Source Position $1 \mathrm{~m}$ & Lining Thickness $(\mu \mathrm{m})$ & \\
\hline \multicolumn{3}{|c|}{ Boron metal lining $(2.34 \mathrm{~g} / \mathrm{cc})$} \\
\hline & 0.50 & $-29 \%$ \\
\hline & 0.75 & $12 \%$ \\
\hline & 1.00 & $30 \%$ \\
\hline & 2.00 & $39 \%$ \\
\hline \multicolumn{3}{|l|}{ BN lining (3.45 g/cc) } \\
\hline & 0.50 & $-50 \%$ \\
\hline & 0.75 & $-51 \%$ \\
\hline & 1.00 & $-29 \%$ \\
\hline & 2.00 & $-27 \%$ \\
\hline \multicolumn{3}{|l|}{$\mathrm{B}_{4} \mathrm{C}$ lining $(2.52 \mathrm{~g} / \mathrm{cc})$} \\
\hline & 0.50 & $-35 \%$ \\
\hline & 0.75 & $-15 \%$ \\
\hline & 1.00 & $2 \%$ \\
\hline & 2.00 & $9 \%$ \\
\hline
\end{tabular}

It is seen that the best agreement is found for a lining thickness of $0.75 \mu \mathrm{m}$ of boron metal, or 2 $\mu \mathrm{m}$ of $\mathrm{BN}$, or $1 \mu \mathrm{m}$ of $\mathrm{B}_{4} \mathrm{C}$. Overall, the results from modeling of individual tubes shows that, depending upon the lining composition and thickness, the results can be within about $10 \%$ of the experimental results.

All further modeling work for the project will utilize a lining thickness of $0.75 \mu \mathrm{m}$ of boron metal since that is seen to be an adequate description. 


\section{Model Comparison for the Multi-Tube Panel}

The simulations for the multi-tube NDM panel were performed using MCNPX, version 2.70, with models based upon design information provided by GE Reuter Stokes.

\subsection{Model of the GE Reuter Stokes Panel}

The ${ }^{10} \mathrm{~B}$-based neutron detection module (NDM) from GE Reuter Stokes consists of an array of 20 , identical boron-lined proportional tubes encased within a rectangular panel, which, except for opening at one end, is filled with high-density polyethylene (HDPE). To help visualize how the HDPE panel and the boron-lined tubes were implemented in the GE Reuter Stokes "B2" model, two screen-captures showing the front and end cross-sectional views through the center of the model are shown in Figure 4.1. In the figure, the HDPE material is shown as light blue, the airfilled regions are shown as grey, and the proportional gas within the tubes is shown as yellow. On the scale used for these two views, the outer walls and the thinner lining cannot be distinguished, and appear as thin black lines along the perimeter of the tubes.

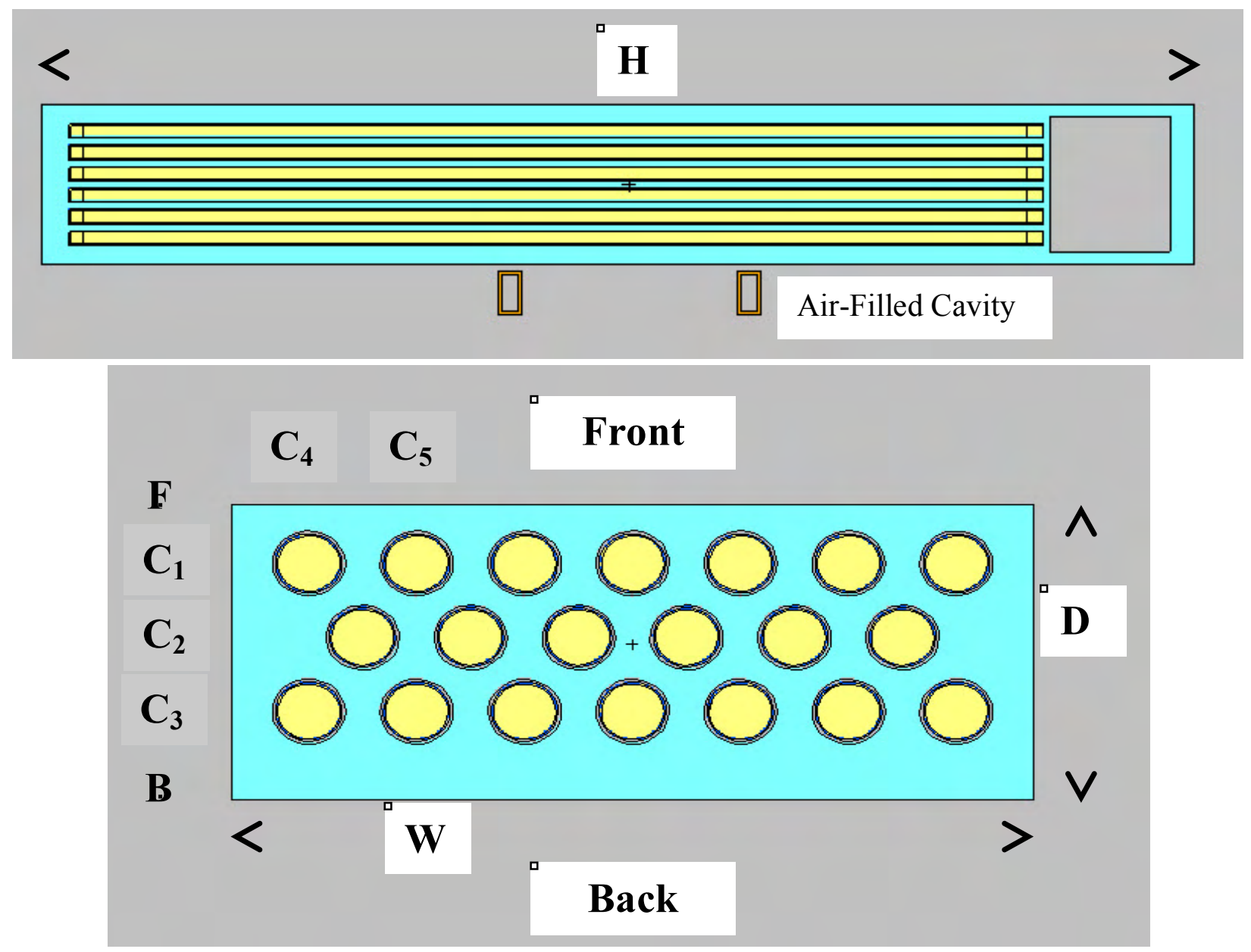

Figure 4.1. Screen captures showing cross-sectional views from the front (top) and end (bottom). 
The NDM panel has on overall height (H), width (W), and depth (D) of $213 \mathrm{~cm}(84.0$ "), $30 \mathrm{~cm}$ (12.0"), and $12.7 \mathrm{~cm}$ (5.0"), respectively. The opening at one end for preamp connections is 26.2 cm (10.3") W, $7.6 \mathrm{~cm}(3.0 ") \mathrm{D}$, and $22.2 \mathrm{~cm}(8.74 ") \mathrm{H}$. At the side of this opening closest to the tubes is a $5.7 \mathrm{~cm}(2.25$ ") $\mathrm{H}$ aluminum connector box that couples two high-voltage "HN" connectors to the central electrodes of the tubes. The remaining $(16.5 \mathrm{~cm}$ [6.49"] $\mathrm{H})$ space in the opening is an air-filled cavity that allows for connecting the external electronics used to process the output from the tubes. For simplicity, this opening was modeled by omitting the aluminum connector box and treating the entire $(22.2 \mathrm{~cm}$ [8.74"] $\mathrm{H})$ volume as an air-filled cavity.

The tubes in the NDM have outer dimensions of $2.54 \mathrm{~cm}\left(1.0^{\prime \prime}\right)$ diameter and $180 \mathrm{~cm}(71 ") \mathrm{H}$, and $0.8 \mathrm{~mm}(0.032 ")$ thick aluminum walls. They are filled with a mixture of $\mathrm{Ar}$ and $\mathrm{CO}_{2}$ gas to a pressure of about $1 / 3^{\text {rd }}$ atmosphere at 20 degrees $C$. The volume fractions of these gases were assumed to be $90 \% \mathrm{Ar}$ and $10 \% \mathrm{CO}_{2}$, the same ratio as $\mathrm{P} 10$ proportional gas, which uses $\mathrm{CH}_{4}$ instead of $\mathrm{CO}_{2}$. Because the proportion of volumes actually used was not known, a variation of that ratio was made to evaluate how that uncertainty in the model would affect the overall results. Also not precisely known was the composition and effective thickness of the thin boron lining. For this study, the lining was treated as a uniform layer of solid ${ }^{10} \mathrm{~B}$ at a density of 2.34 $\mathrm{g} / \mathrm{cc}$. The thickness of this layer was taken as one of the key unknown parameters of the model, for which a range of values were calculated.

The vertical details of the tubes and their position within the panel are as follows. The end of the tubes furthest away from the connector box is $5.1 \mathrm{~cm} \mathrm{(2.0")} \mathrm{from} \mathrm{the} \mathrm{outside} \mathrm{end} \mathrm{of} \mathrm{the} \mathrm{panel.}$ This value is the thickness of the HDPE at that end of the panel, and end of the tubes were modeled to start at that same position. The dead-zone at that end of the tube is $2.5 \mathrm{~cm}(0.97 ")$ from the tube outer end, the active height is $174.8 \mathrm{~cm}(68.83 ")$, and the dead-zone at the other (connector) end of the tube is $3.0 \mathrm{~cm}\left(1.2^{\prime \prime}\right)$ from connector end of the tube. That end of the tube is $1.4 \mathrm{~cm}(0.56 ")$ from the $22.2 \mathrm{~cm}(8.74 ") \mathrm{H}$ cavity, and the panel thickness of polyethylene at top of the cavity is $4.3 \mathrm{~cm}(1.7$ ").

Some of the details described above for the NDM panel and the vertical positions of the tubes can be seen in the top part of Figure 4.1, which shows the front (or W-H) cross-sectional view of the model in the plane at the mid-point of the $\mathrm{D}$ dimension. As seen in the end-view of the model, the 20 tubes within the panel are distributed in a 7-6-7 staggered array. For reference, the labels $\mathrm{C} 1, \mathrm{C} 2$, and $\mathrm{C} 3$, are used for the centerline positions of front, middle, and back rows of tubes along the $\mathrm{D}$-dimension, respectively. The distance from the front $(\mathrm{F})$ of the panel to $\mathrm{C} 1$ is $2.54 \mathrm{~cm}\left(1.0^{\prime \prime}\right)$, and from $\mathrm{C} 1$ to $\mathrm{C} 2$ and $\mathrm{C} 2$ to $\mathrm{C} 3$ is $3.18 \mathrm{~cm}\left(1.25^{\prime \prime}\right)$. In the W-dimension, the labels $\mathrm{C} 4$ and $\mathrm{C} 5$ are used for the centerline positions of the first two consecutive front and backrow tubes. The distance from the left end of the panel to $\mathrm{C} 4$ is $2.93 \mathrm{~cm}\left(1.15^{\prime \prime}\right)$, and the distance from $\mathrm{C} 4$ to $\mathrm{C} 5$ is $4.10 \mathrm{~cm}(1.61 ")$. The $\mathrm{W}$-positions of the middle row of tubes is half-way between those in the front (or back) row, giving the center of the left-most middle tube to be 4.98 $\mathrm{cm}(1.96 ")$ from the left end of the panel. In that dimension, the position of tubes is symmetric from either side of the panel. So the value of $\mathrm{C} 4$ from the left end of the panel and the distance (C5-C4) between tubes is all that is needed to specify the positions for the other tubes in that dimension. Also used in the model is also a small air gap of $1 \mathrm{~mm}(0.04 ")$ between the HDPE and the $\mathrm{Al}$ outer walls of the tubes.

The outer dimensional values for the panel given above were measured from the NDM unit. The geometric and material composition details of the tubes sealed within the NDM panel were 
obtained from engineering drawings or other information provided by GE Reuter Stokes to PNNL in private communications. ${ }^{1}$

\subsection{The Modeled Measurement Environment}

The model "environment" was constructed as a large, air-filled volume that included only the components deemed important to simulate the actual environment in which the PNNL measurements were made. This included a simplified model of the support platform used to position the NDM in a horizontal orientation, the "PolyPig" neutron source holder which contained the ${ }^{252} \mathrm{Cf}$ source used for all these PNNL measurements, the tripod upon which the PolyPig was placed, and finally a $25.4 \mathrm{~cm}\left(10^{\prime \prime}\right)$ thick large floor slab of common Portland cement upon which the NDM support platform and the source tripod were placed. A threedimensional view of the GE Reuter Stokes B2 in this model environment is shown in Figure 4.2, where the source is 1-meter from the front right end of the NDM (the connector box end). The midpoint of the NDM and the source (inside of the PolyPig) are $1.50 \mathrm{~m}$ above ground level.

The support platform model was modeled from open-ended, rectangular steel pipes, with 6.35 $\mathrm{mm}(0.25 ")$ wall thickness, and outer dimensions adjusted to approximate the overall appearance of the platform shown in Figure 2.5. The model of the PolyPig was described above. The density of the common Portland mixture was taken as $2.3 \mathrm{~g} / \mathrm{cc}$. Because the concrete floor was expected to reflect neutrons back into the NDM, a variation of that value was performed to determine the uncertainty in the final results that could results for that part of the environment, and the thickness used $(25.4 \mathrm{~cm})$ was found to be adequate.

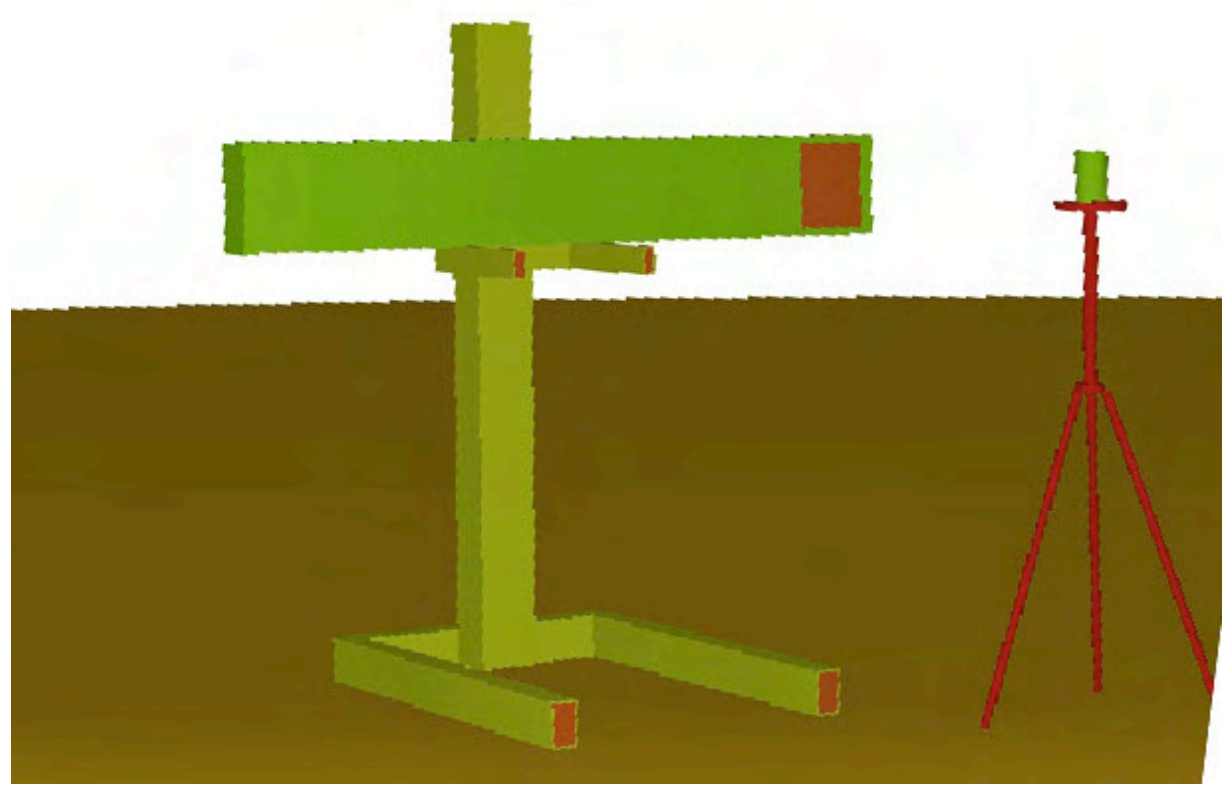

Figure 4.2. Three-dimensional projection of the modeling environment.

\footnotetext{
${ }^{1}$ GE Reuter Stokes engineering drawing B2-2001-1, Rev.1, dated 1/11/2012, specified the tube pattern (Design Version B2); GE Reuter Stokes engineering drawing RS-P7-1000, NC, via email Nov.2009, provided details of the panel interior, specifically vertical positions of the tube ends and dead zones; and GE Reuter Stokes engineering drawing RS-P7-0869-101-1, NC, dated 7/10/2009, provided details on the (Al) used for the tube body shell.
} 


\subsection{Model Results}

Simulations were performed for five source positions: $2 \mathrm{~m}$ from the Front Midpoint of the NDM, $1 \mathrm{~m}$ from the Front Midpoint, $1 \mathrm{~m}$ from the Front Right end, $1 \mathrm{~m}$ from the Front Left end, and 1 $m$ from the Back Midpoint of the NDM (obtained by rotating the NDM in its support platform so the back, with thicker HDPE of the panel, faced the source). For all these positions, both the source (inside the PolyPig) and the midpoint of the NDM were fixed to be $1.5 \mathrm{~m}$ above ground level.

Listed in Table 4.1 are the percent differences between the model results assuming a boron metal lining and the experimental measurements for the GE Reuter Stokes NDM panel. The results are for different boron metal lining thicknesses (rows) and for a lower-energy cut off (LEC) value of $100 \mathrm{keV}$ and a source to moderator distance of $1 \mathrm{~m}$. The boron metal density used for these calculations was $2.34 \mathrm{~g} / \mathrm{cc}$. The experimental values listed below as "Measured" are counts per neutron emitted from the source (scaled up by a factor of 100) with an LEC of $100 \mathrm{keV}$. The values shown in this table for the models are the percent difference between model and experiment (a positive value indicates the model value is larger than the experimental value). Except for the $1 \mathrm{~m}$ Front Midpoint set, there are three rows of results showing the changes over the range of boron-lined thickness values from $0.75 \mu \mathrm{m}$ to $1.25 \mu \mathrm{m}$. For the $1 \mathrm{~m}$ Front Midpoint set, the range of boron-lined thickness was extended to $2 \mu \mathrm{m}$.

Table 4.1. Percent differences between the panel model and measurements as a function of boron metal thickness.

\begin{tabular}{|c|c|c|}
\hline \multicolumn{2}{|r|}{$\overline{\mathrm{LEC}}(\mathrm{MeV})==>$} & \multirow[t]{2}{*}{0.100} \\
\hline Source Position & Lining Thickness $(\mu \mathrm{m})$ & \\
\hline \multirow[t]{6}{*}{ Front 1m Midpoint } & Measured (x100) $==>$ & 0.331 \\
\hline & 0.75 & $26 \%$ \\
\hline & 1.00 & $33 \%$ \\
\hline & 1.25 & $33 \%$ \\
\hline & 1.50 & $31 \%$ \\
\hline & 2.00 & $24 \%$ \\
\hline \multirow[t]{4}{*}{ Front $1 \mathrm{~m}$ Right End } & Measured (x100) & 0.212 \\
\hline & 0.75 & $27 \%$ \\
\hline & 1.00 & $34 \%$ \\
\hline & 1.25 & $35 \%$ \\
\hline \multirow[t]{4}{*}{ Front 1m Left End } & Measured (x100) & 0.197 \\
\hline & 0.75 & $33 \%$ \\
\hline & 1.00 & $40 \%$ \\
\hline & 1.25 & $41 \%$ \\
\hline \multirow[t]{4}{*}{ Back 1m Midpoint } & Measured (x100) & 0.306 \\
\hline & 0.75 & $21 \%$ \\
\hline & 1.00 & $27 \%$ \\
\hline & 1.25 & $28 \%$ \\
\hline
\end{tabular}

Table 4.2 lists similar percent difference results for different models of the boron linings. The boron metal results metal (repeat of Table 4.1) are listed first, then those for the BN (density was $3.45 \mathrm{~g} / \mathrm{cc}$ ) and $\mathrm{B}_{4} \mathrm{C}$ (density was $2.52 \mathrm{~g} / \mathrm{cc}$ ). The source to moderator distance was $1 \mathrm{~m}$ from the front midpoint of the detector for all of the results listed. For reference, the complete set of total 
efficiency results for different LEC and lining thickness values evaluated for this model are given in the Appendix.

Table 4.2. Percent differences for panel model efficiency as a function of boron lining material.

\begin{tabular}{|c|c|c|}
\hline \multicolumn{2}{|r|}{ LEC $(\mathrm{MeV})==>$} & 0.100 \\
\hline Source Position & Lining Thickness $(\mu \mathrm{m})$ & \\
\hline \multicolumn{3}{|c|}{ boron metal lining $(2.34 \mathrm{~g} / \mathrm{cc})$} \\
\hline & 0.75 & $26 \%$ \\
\hline & 1.00 & $33 \%$ \\
\hline & 1.25 & $33 \%$ \\
\hline & 1.50 & $31 \%$ \\
\hline & 2.00 & $24 \%$ \\
\hline \multicolumn{3}{|c|}{ BN lining (3.45 g/cc) } \\
\hline & 0.75 & $-14 \%$ \\
\hline & 1.00 & $-11 \%$ \\
\hline & 1.25 & $-10 \%$ \\
\hline & 1.50 & $-10 \%$ \\
\hline & 2.00 & $-15 \%$ \\
\hline \multicolumn{3}{|c|}{$\mathrm{B}_{4} \mathrm{C}$ lining $(2.52 \mathrm{~g} / \mathrm{cc})$} \\
\hline & 0.75 & $12 \%$ \\
\hline & 1.00 & $19 \%$ \\
\hline & 1.25 & $19 \%$ \\
\hline & 1.50 & $18 \%$ \\
\hline & 2.00 & $13 \%$ \\
\hline
\end{tabular}

Generally, the model over predicts the efficiency compared to the experimental results by $\sim 30 \%$. The single tube models produced closer agreement with experiment. Further study will be performed to see whether improvements can be realized in the agreement between model and experiment.

As examples of the pulse-height spectra associated with the results listed in Table 4.1, simulated spectra for the 1-m Front Midpoint case are shown in Figures 4.3 through 4.5. Each of these figures consists of a composite chart that shares the same energy abscissa. The top chart of each shows the lithium pulse-height, the middle chart the alpha pulse-height, and the bottom chart the pulse-height from their sum. Also shown in these pulse-height spectra are four yellow diamond symbols with vertical dashed lines. They mark the upper limits of kinetic energies allowed for each of the reaction products. They are determined by sharing in proportion to their mass the reaction Q-values for the two different ${ }^{7} \mathrm{Li}$ final states that result from $\mathrm{n}$-capture on ${ }^{10} \mathrm{~B}$. For the predominant branch $(\sim 94 \%)$ of that capture reaction, the ${ }^{7} \mathrm{Li}$ nucleus is left in its excited state with $\mathrm{Q}=2.310 \mathrm{MeV}$, giving $0.840 \mathrm{MeV}$ and $1.470 \mathrm{MeV}$ for the initial kinetic energies of the ${ }^{7} \mathrm{Li}$ and ${ }^{4} \mathrm{He}$, respectively. For the less probable ${ }^{7} \mathrm{Li}$ ground state branch, $\mathrm{Q}=2.792 \mathrm{MeV}$, giving higher initial energies of $1.015 \mathrm{MeV}$ and $1.777 \mathrm{MeV}$, respectively. All results are for a gas pressure of $0.3 \mathrm{~atm}$.

Figure 4.3 shows the effects on the pulse-height shapes that occur by changing the boron metal thickness over the range of $0.75 \mu \mathrm{m}$ to $2.0 \mu \mathrm{m}$. Those results show that a clearly separated double-hump total shape (red curve in bottom chart) can become a much broader shape (black curve) that shows a less distinct separation from the two reaction product contributions. 
Figures 4.4 and 4.5 show similar results for the $\mathrm{BN}$ and $\mathrm{B}_{4} \mathrm{C}$ linings, respectively. A future report will discuss the comparison of modeled to measured pulse heights and their shape dependence on the details of the boron lining and proportional gas.

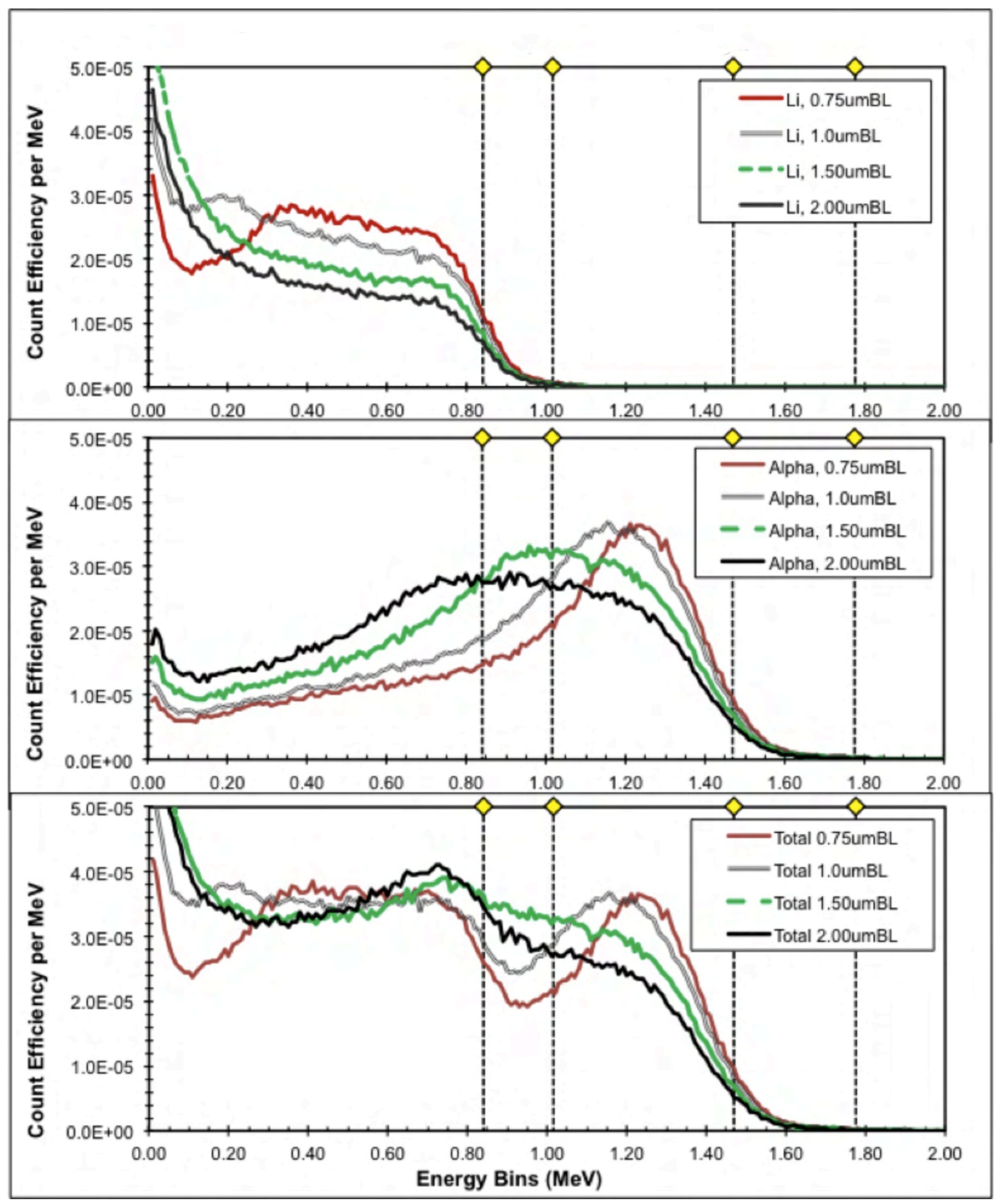

Figure 4.3. Effects of Boron Metal Lining Thickness on Pulse-Height Spectra. 


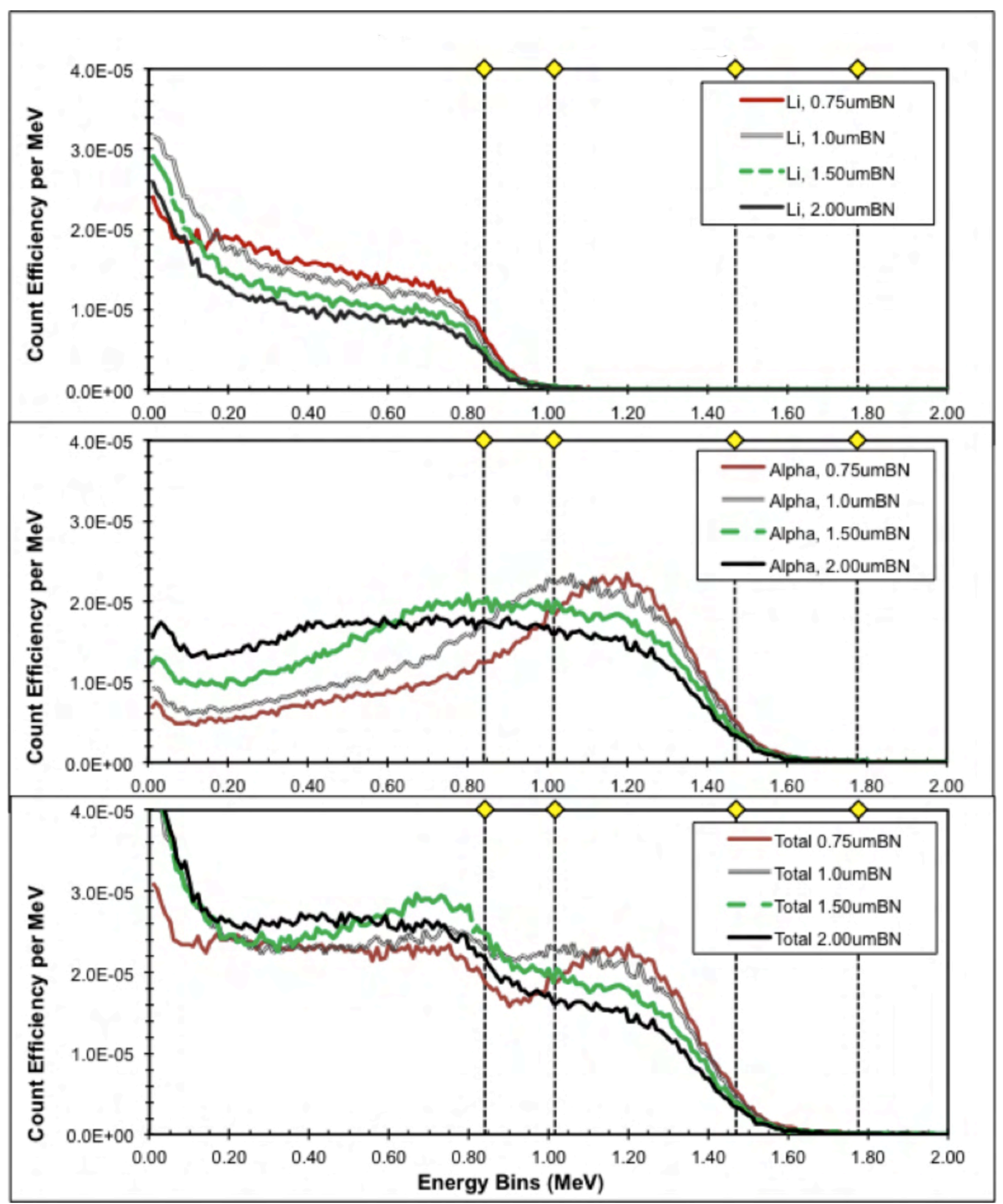

Figure 4.4. Effects of Boron Nitride Lining Thickness on Pulse-Height Spectra. 


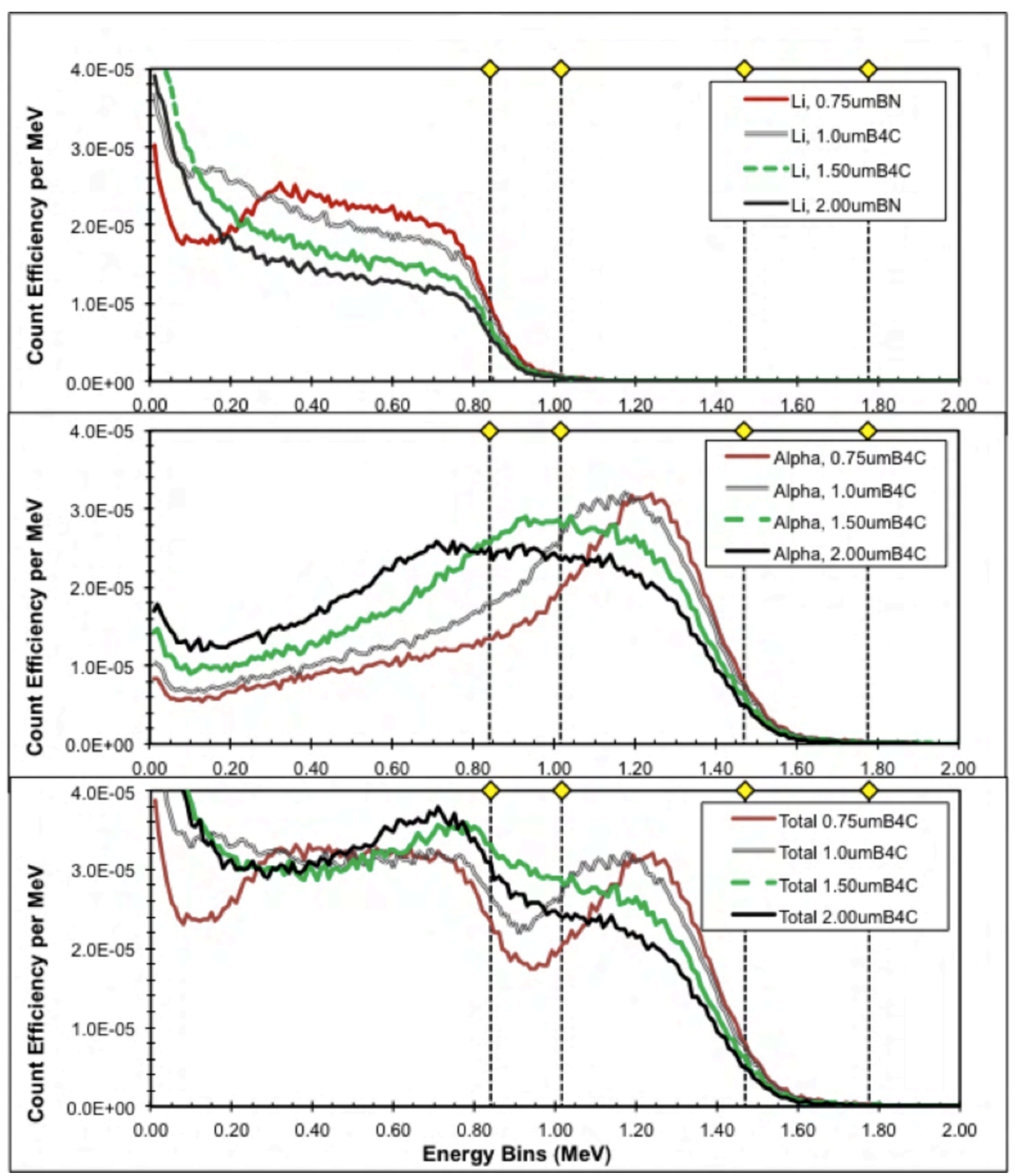

Figure 4.5. Effects of Boron Carbide Lining Thickness on Pulse-Height Spectra.

Figure 4.6 shows the effects of adding $\mathrm{CO}_{2}$ to the Ar proportional gas. The results compare a pure $100 \%$ Ar gas to a $90 / 10$ by volume ratio and an $80 / 20$ by volume ratio of $\mathrm{Ar}$ to $\mathrm{CO}_{2}$. There is a clear, albeit small, effect when the ratio is changed from $100 \%$ to $90 / 10$, however, adding more $\mathrm{CO}_{2}$ (at least to the $20 \%$ amount) appears to have very little additional effect. 


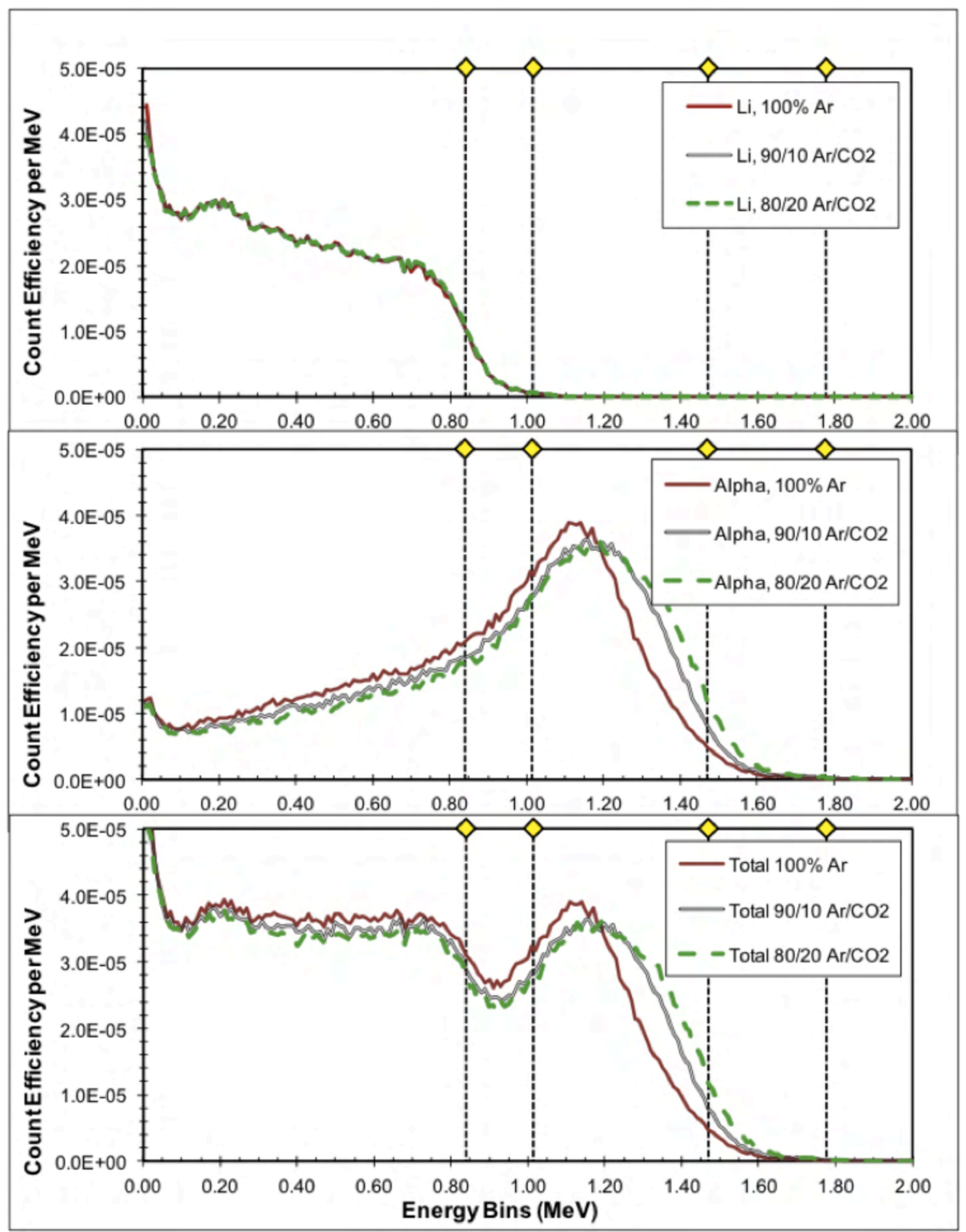

Figure 4.6. Effects on Pulse-Height Spectra from $\mathrm{CO}_{2}$ in Proportional Gas.

Page 25 of 43 
Finally, to estimate the effect that the concrete floor has upon the total count rates, the density of the common Portland cement mixture was change from $2.3 \mathrm{~g} / \mathrm{cc}$ to $0.23 \mathrm{~g} / \mathrm{cc}$ and the cases for the $2 \mathrm{~m}$ Front Midpoint and $1 \mathrm{~m}$ Front Midpoint were re-evaluated. The floor is the most important environmental feature affecting the model results. Reducing the density by a factor of 10 resulted in an $8 \%$ reduction in the $2 \mathrm{~m}$ results and a $4 \%$ reduction in the $1 \mathrm{~m}$ case. This magnitude of effect is considered an acceptable range of error for the rather simply modeled environment used for this study.

Overall, the multitube model was validated against the experimental measurements to the 20$30 \%$ level of accuracy. 


\section{Conclusions}

The purpose of this report was to benchmark the accuracy of the new MCNPX methods for simulating boron-lined proportional detectors by comparing model results to experimental measurements for two types of neutron detection systems based on boron-lined tubes. The first of these comparisons was performed using simple individual tubes, and measurements were made with a bare tube and with the tube moderated by inserting it into a block of HDPE. The second system modeled and measured was a pre-built Neutron Detection Module "panel" that contained an array of $20{ }^{10} \mathrm{~B}$-lined proportional tubes embedded within a larger box filled with HDPE. The tubes in this system are similar to, but longer than, the individual tubes used in the first set of comparisons.

The measure of comparison used in this study was the total count rates. The models evaluated in this study for individual tubes agreed within a few percent with measurements for close geometries, with the models over predicting response at larger distances of 1 to $2 \mathrm{~m}$. It was found that these comparisons could be improved by modifying the effects of the environment (floor and walls), providing agreement to better than $6 \%$ at all distances.

The models of multi-tube systems tended to over-predict the measured values by $20-30 \%$. This may be due to the accuracy of the modeled lining material or thickness, or other modeling assumptions that are incorrect, such as room reflections. Models for ${ }^{3} \mathrm{He}$ based systems have produced this, or better, level of agreement with experiment. The underlying causes of this uncertainty will be further examined in the models constructed for simulating the coincidence counter systems that will be evaluated in the next phase of this project.

The strategy for this project going forward is to use the model parameters that provide adequate comparison to experiment, which may or may not be related to the actual material or thickness of the lining. No information from the vendor on the actual boron coating was used in this study. A boron metal thickness of $0.75 \mu \mathrm{m}$ appears to be an adequate value to use for models of boronlined tube systems based upon the current tubes supplied by General Electric Reuter-Stokes.

This work will be extended to more comparisons of model and experiment to improve the agreement that can be obtained. This includes direct comparisons of a boron-lined tube to a ${ }^{3} \mathrm{He}$ tube in a close geometry.

The results from this work will be applied to the development of coincidence collar models (UNCL-I and UNCL-II) using boron-lined tubes. 


\section{References}

Ely JH, ER Siciliano, MT Swinhoe. 2011. Alternatives to Helium-3 for Neutron Multiplicity Detectors. Technical Report PNNL-SA-77627, Pacific Northwest National Laboratory, Richland, Washington. 52 ${ }^{\text {nd }}$ INMM Meeting, Palm Desert, CA, 17-21 July 2011.

Ely JH, AT Lintereur, ER Siciliano. 2011b. Interim Report on the Optimization and Feasibility Studies for the Neutron Detection without Helium-3 Project. Technical Report PNNL-20952, Pacific Northwest National Laboratory, Richland, Washington.

Kouzes RT, JH Ely, AT Lintereur, ER Siciliano. 2012. "Introduction to Neutron Coincidence Counter Design Based on Boron-10.” PNNL Report PNNL-21090.

Lintereur AT, RT Kouzes, JH Ely, LE Erikson, and ER Siciliano. 2010. Boron Lined Neutron Detector Measurements. PNNL-18938, Pacific Northwest National Laboratory, Richland, WA.

MCNPX. Pelowitz DB (ed.). 2011. “MCNPX User's Manual”, Version 2.7.0. Los Alamos National Laboratory Report LA-CP-11-00438.

Siciliano ER, JH Ely, RT Kouzes, ML Woodring. 2010. Simulating Boron-Based Detectors with MCNPX. Technical Report PNNL-SA-71579, Pacific Northwest National Laboratory, Richland, Washington.

Siciliano ER, RT Kouzes. 2012. Boron-10 Lined Proportional Counter Wall Effects. Technical Report PNNL-21368, Pacific Northwest National Laboratory, Richland, Washington. 


\section{Acknowledgements}

The United States Department of Energy Office of Nuclear Safeguards (NA-241) supported this work. Pacific Northwest National Laboratory is operated for the United States Department of Energy under contract DE-AC05-76RLO 1830. Azaree Lintereur is a post-Masters Research Assistant supported at Pacific Northwest National Laboratory by the Next Generation Safeguards Initiative, Office of Nuclear Safeguards and Security, National Nuclear Security Administration. 


\section{Appendix A: Stopping Distance}

The maximum distances traveled by the reaction products from neutron capture on ${ }^{10} \mathrm{~B}$ is an important aspect of the model. Figure 8.1 shows the range/density values for the alpha particle reaction products in three possible linings (pure boron, boron nitride, and boron carbide) and in the proportional gas. Figure 8.2 similarly shows the range/density values of the ${ }^{7} \mathrm{Li}$ particle. In both figures, the red lines show the maximum energy of the particles for the ground and excited final state of the ${ }^{7} \mathrm{Li}$ particle.

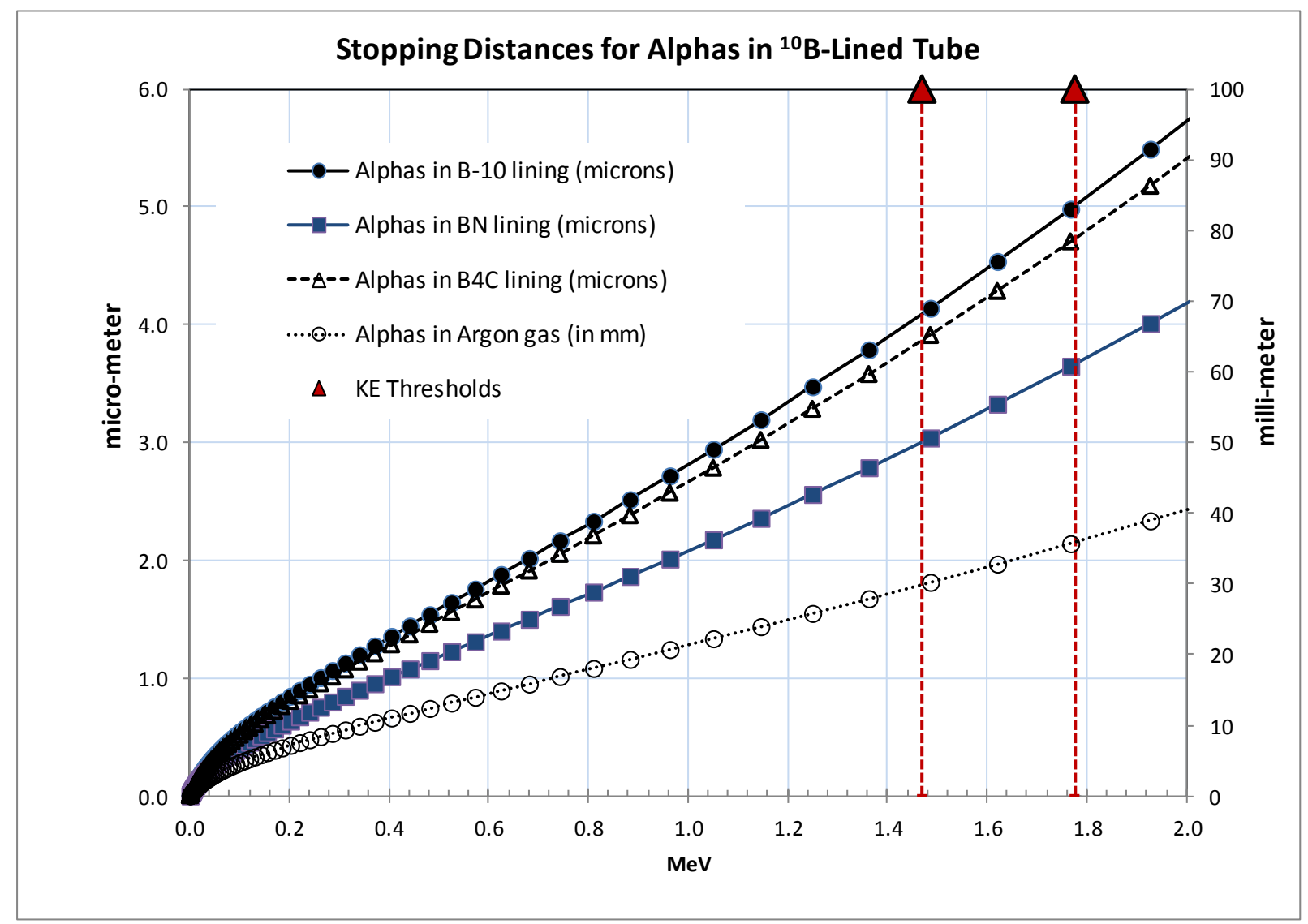

Figure 8.1. Stopping distance for alpha particles. 


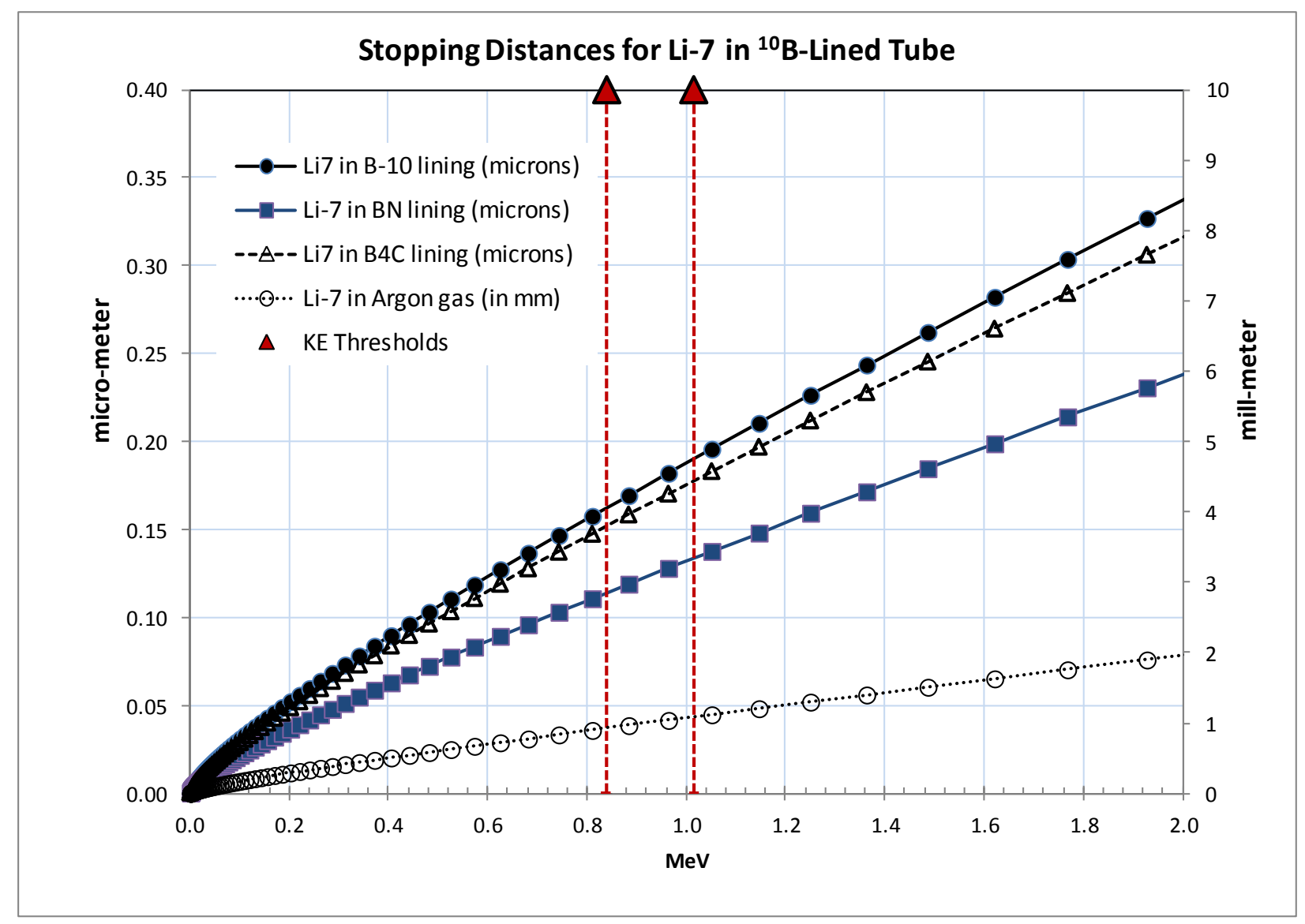

Figure 8.2. Stopping distance for ${ }^{7} \mathrm{Li}$ particles. 


\section{Appendix B: Complete Set of Moderated Single Tube Results}

Table 9.1 provides detailed results of the modeling of an individual boron-lined tube in a polyethylene moderator assuming pure boron metal, as discussed in Section 3, and comparison to experiment. The tube pressure was assumed to be one atmosphere (now known to be about one third atmosphere). The first column of the table gives the distance between the source and the front of the moderator (from 10 to $200 \mathrm{~cm}$ ). The second column provides the energy threshold used for each row of the table (in channel number and keV). The next three columns provide the experimental results for each of the two tubes tested, and the average in counts per second per emitted neutron. The next several columns in the first set of rows provide the model results for comparison to the experimental results, where the model number is the thickness of the boron lining in micrometers. The second group of rows for each distance gives the percent difference between model and experiment (model minus experiment divided by experiment). A positive number indicates the model overestimates the response. It is seen that the best consistent agreement is found for lining thicknesses of $0.75 \mu \mathrm{m}$ and $4 \mu \mathrm{m}$ of boron metal. The agreement is seen to be better than $10 \%$ for several of the threshold energies. The agreement gets worse with increasing threshold energy (matching model and experiment), which may indicate the details of the assumed lining material and gas, which effect the pulse height distribution, are not completely accurate. The model agreement gets worse at larger distances, which may indicate that environmental effects or detector end effects are not adequately included in the model.

\begin{tabular}{|c|c|c|c|c|c|c|c|c|c|c|c|c|}
\hline \multicolumn{2}{|c|}{ source to poly distance } & $\begin{array}{c}\text { Exp Tube } \\
1\end{array}$ & $\begin{array}{c}\text { Exp Tube } \\
2\end{array}$ & $\begin{array}{c}\text { Exp } \\
\text { Average }\end{array}$ & $\begin{array}{c}\text { model: } \\
0.5\end{array}$ & $\begin{array}{c}\text { model: } \\
0.75\end{array}$ & $\begin{array}{c}\text { model: } \\
1\end{array}$ & $\begin{array}{c}\text { model: } \\
2\end{array}$ & $\begin{array}{c}\text { model: } \\
2.5\end{array}$ & $\begin{array}{c}\text { model: } \\
3\end{array}$ & $\begin{array}{c}\text { model: } \\
4\end{array}$ & $\begin{array}{c}\text { model: } \\
5\end{array}$ \\
\hline \multicolumn{13}{|c|}{10} \\
\hline \multirow[t]{18}{*}{$\mathbf{c m}$} & no cut & 0.00196 & 0.00190 & 0.00193 & 0.00142 & 0.00183 & 0.00213 & 0.00239 & 0.00236 & 0.00223 & 0.00196 & 0.00172 \\
\hline & chan $20(80 \mathrm{keV})$ & 0.00178 & 0.00173 & 0.00176 & 0.00135 & 0.00173 & 0.00200 & 0.00219 & 0.00212 & 0.00201 & 0.00173 & 0.00151 \\
\hline & chan $25(100 \mathrm{keV})$ & 0.00173 & 0.00169 & 0.00171 & 0.00134 & 0.00170 & 0.00197 & 0.00213 & 0.00208 & 0.00196 & 0.00168 & 0.00148 \\
\hline & chan $30(120 \mathrm{keV})$ & 0.00168 & 0.00164 & 0.00166 & 0.00133 & 0.00168 & 0.00193 & 0.00209 & 0.00203 & 0.00191 & 0.00163 & 0.00143 \\
\hline & chan $37(150 \mathrm{keV})$ & 0.00161 & 0.00157 & 0.00159 & 0.00132 & 0.00167 & 0.00189 & 0.00204 & 0.00198 & 0.00185 & 0.00157 & 0.00138 \\
\hline & chan $50(200 \mathrm{keV})$ & 0.00151 & 0.00147 & 0.00149 & 0.00130 & 0.00161 & 0.00182 & 0.00196 & 0.00189 & 0.00178 & 0.00149 & 0.00132 \\
\hline & chan $75(300 \mathrm{keV})$ & 0.00133 & 0.00130 & 0.00131 & 0.00125 & 0.00153 & 0.00169 & 0.00182 & 0.00173 & 0.00162 & 0.00134 & 0.00119 \\
\hline & chan $87(350 \mathrm{keV})$ & 0.00124 & 0.00122 & 0.00123 & 0.00123 & 0.00147 & 0.00163 & 0.00175 & 0.00167 & 0.00152 & 0.00127 & 0.00113 \\
\hline & chan $100(400 \mathrm{keV})$ & 0.00116 & 0.00113 & 0.00114 & 0.00119 & 0.00140 & 0.00156 & 0.00167 & 0.00158 & 0.00143 & 0.00120 & 0.00107 \\
\hline & diff no cut & & & & $-27 \%$ & $-5 \%$ & $10 \%$ & $23 \%$ & $22 \%$ & $15 \%$ & $1 \%$ & $-11 \%$ \\
\hline & diff $80 \mathrm{keV}$ cut & & & & $-23 \%$ & $-2 \%$ & $14 \%$ & $25 \%$ & $21 \%$ & $14 \%$ & $-1 \%$ & $-14 \%$ \\
\hline & diff $100 \mathrm{keV}$ cut & & & & $-22 \%$ & $0 \%$ & $15 \%$ & $25 \%$ & $22 \%$ & $15 \%$ & $-2 \%$ & $-14 \%$ \\
\hline & diff $120 \mathrm{keV}$ cut & & & & $-20 \%$ & $1 \%$ & $16 \%$ & $26 \%$ & $22 \%$ & $15 \%$ & $-2 \%$ & $-14 \%$ \\
\hline & diff $150 \mathrm{keV}$ cut & & & & $-17 \%$ & $5 \%$ & $19 \%$ & $28 \%$ & $24 \%$ & $16 \%$ & $-1 \%$ & $-13 \%$ \\
\hline & diff $200 \mathrm{keV}$ cut & & & & $-13 \%$ & $8 \%$ & $22 \%$ & $31 \%$ & $27 \%$ & $20 \%$ & $0 \%$ & $-11 \%$ \\
\hline & diff $300 \mathrm{keV}$ cut & & & & $-5 \%$ & $17 \%$ & $29 \%$ & $39 \%$ & $32 \%$ & $23 \%$ & $2 \%$ & $-9 \%$ \\
\hline & diff $350 \mathrm{keV}$ cut & & & & $0 \%$ & $19 \%$ & $33 \%$ & $42 \%$ & $36 \%$ & $24 \%$ & $4 \%$ & $-8 \%$ \\
\hline & diff $400 \mathrm{keV}$ cut & & & & $4 \%$ & $22 \%$ & $36 \%$ & $46 \%$ & $38 \%$ & $25 \%$ & $5 \%$ & $-7 \%$ \\
\hline
\end{tabular}




\begin{tabular}{|c|c|c|c|c|c|c|c|c|c|c|c|c|}
\hline \multicolumn{2}{|c|}{ source to poly distance } & \multirow[t]{2}{*}{$\begin{array}{c}\text { Exp Tube } \\
1 \\
\end{array}$} & \multirow[t]{2}{*}{$\begin{array}{c}\text { Exp Tube } \\
2 \\
\end{array}$} & \multirow[t]{2}{*}{$\begin{array}{c}\text { Exp } \\
\text { Average }\end{array}$} & \multirow[t]{2}{*}{$\begin{array}{c}\text { model: } \\
0.5 \\
\end{array}$} & \multirow[t]{2}{*}{$\begin{array}{c}\text { model: } \\
0.75 \\
\end{array}$} & \multirow[t]{2}{*}{$\begin{array}{c}\text { model: } \\
1 \\
\end{array}$} & \multirow[t]{2}{*}{$\begin{array}{c}\text { model: } \\
2 \\
\end{array}$} & \multirow[t]{2}{*}{$\begin{array}{l}\text { model: } \\
2.5 \\
\end{array}$} & \multirow[t]{2}{*}{$\begin{array}{c}\text { model: } \\
\mathbf{3} \\
\end{array}$} & \multirow[t]{2}{*}{$\begin{array}{c}\text { model: } \\
4 \\
\end{array}$} & \multirow[t]{2}{*}{$\begin{array}{c}\text { model: } \\
5\end{array}$} \\
\hline \multirow{21}{*}{$\begin{array}{l}25 \\
\mathrm{~cm}\end{array}$} & & & & & & & & & & & & \\
\hline & no cut & 0.00075 & 0.00075 & 0.00075 & 0.00057 & 0.00072 & 0.00083 & 0.00098 & 0.00096 & 0.00091 & 0.00076 & 0.00066 \\
\hline & chan $20(80 \mathrm{keV})$ & 0.00068 & 0.00068 & 0.00068 & 0.00055 & 0.00068 & 0.00076 & 0.00089 & 0.00088 & 0.00080 & 0.00068 & 0.00058 \\
\hline & chan $25(100 \mathrm{keV})$ & 0.00066 & 0.00066 & 0.00066 & 0.00054 & 0.00067 & 0.00075 & 0.00088 & 0.00086 & 0.00078 & 0.00066 & 0.00056 \\
\hline & chan $30(120 \mathrm{keV})$ & 0.00064 & 0.00064 & 0.00064 & 0.00054 & 0.00066 & 0.00074 & 0.00086 & 0.00084 & 0.00076 & 0.00064 & 0.00055 \\
\hline & chan $37(150 \mathrm{keV})$ & 0.00062 & 0.00062 & 0.00062 & 0.00053 & 0.00065 & 0.00072 & 0.00083 & 0.00081 & 0.00074 & 0.00062 & 0.00053 \\
\hline & chan $50(200 \mathrm{keV})$ & 0.00057 & 0.00058 & 0.00058 & 0.00052 & 0.00063 & 0.00069 & 0.00079 & 0.00076 & 0.00069 & 0.00058 & 0.00049 \\
\hline & chanl $62(250 \mathrm{keV})$ & 0.00054 & 0.00055 & 0.00054 & 0.00051 & 0.00061 & 0.00067 & 0.00077 & 0.00073 & 0.00066 & 0.00054 & 0.00046 \\
\hline & chan $75(300 \mathrm{keV})$ & 0.00051 & 0.00051 & 0.00051 & 0.00051 & 0.00059 & 0.00064 & 0.00073 & 0.00070 & 0.00062 & 0.00052 & 0.00044 \\
\hline & chan $87(350 \mathrm{keV})$ & 0.00047 & 0.00048 & 0.00048 & 0.00049 & 0.00056 & 0.00061 & 0.00071 & 0.00066 & 0.00059 & 0.00049 & 0.00042 \\
\hline & chan $100(400 \mathrm{keV})$ & 0.00044 & 0.00045 & 0.00045 & 0.00048 & 0.00054 & 0.00059 & 0.00068 & 0.00062 & 0.00055 & 0.00046 & 0.00039 \\
\hline & diff no cut & & & & $-24 \%$ & $-3 \%$ & $10 \%$ & $31 \%$ & $28 \%$ & $21 \%$ & $2 \%$ & $-12 \%$ \\
\hline & diff $80 \mathrm{keV}$ cut & & & & $-20 \%$ & $0 \%$ & $13 \%$ & $32 \%$ & $29 \%$ & $18 \%$ & $0 \%$ & $-14 \%$ \\
\hline & diff $100 \mathrm{keV}$ cut & & & & $-18 \%$ & $2 \%$ & $14 \%$ & $33 \%$ & $30 \%$ & $18 \%$ & $0 \%$ & $-14 \%$ \\
\hline & diff $120 \mathrm{keV}$ cut & & & & $-16 \%$ & $3 \%$ & $16 \%$ & $34 \%$ & $30 \%$ & $18 \%$ & $0 \%$ & $-14 \%$ \\
\hline & diff $150 \mathrm{keV}$ cut & & & & $-13 \%$ & $6 \%$ & $17 \%$ & $34 \%$ & $31 \%$ & $19 \%$ & $0 \%$ & $-14 \%$ \\
\hline & diff $200 \mathrm{keV}$ cut & & & & $-10 \%$ & $9 \%$ & $19 \%$ & $37 \%$ & $32 \%$ & $20 \%$ & $0 \%$ & $-15 \%$ \\
\hline & diff $250 \mathrm{keV}$ cut & & & & $-5 \%$ & $12 \%$ & $23 \%$ & $41 \%$ & $34 \%$ & $21 \%$ & $0 \%$ & $-15 \%$ \\
\hline & diff $300 \mathrm{keV}$ cut & & & & $-1 \%$ & $16 \%$ & $26 \%$ & $44 \%$ & $37 \%$ & $23 \%$ & $2 \%$ & $-13 \%$ \\
\hline & diff $350 \mathrm{keV}$ cut & & & & $3 \%$ & $18 \%$ & $29 \%$ & $48 \%$ & $38 \%$ & $23 \%$ & $2 \%$ & $-12 \%$ \\
\hline & diff $400 \mathrm{keV}$ cut & & & & $8 \%$ & $21 \%$ & $33 \%$ & $52 \%$ & $39 \%$ & $23 \%$ & $2 \%$ & $-12 \%$ \\
\hline \multirow{21}{*}{$\begin{array}{l}\mathbf{5 0} \\
\mathrm{cm}\end{array}$} & & & & & & & & & & & & \\
\hline & no cut & 0.00029 & 0.00030 & 0.00029 & 0.00023 & 0.00028 & 0.00033 & 0.00038 & 0.00038 & 0.00037 & 0.00031 & 0.00032 \\
\hline & chan $20(80 \mathrm{keV})$ & 0.00026 & 0.00027 & 0.00027 & 0.00022 & 0.00027 & 0.00031 & 0.00034 & 0.00035 & 0.00034 & 0.00027 & 0.00029 \\
\hline & chan $25(100 \mathrm{keV})$ & 0.00025 & 0.00026 & 0.00026 & 0.00021 & 0.00026 & 0.00031 & 0.00033 & 0.00034 & 0.00033 & 0.00027 & 0.00028 \\
\hline & chan $30(120 \mathrm{keV})$ & 0.00025 & 0.00026 & 0.00025 & 0.00021 & 0.00026 & 0.00031 & 0.00033 & 0.00033 & 0.00032 & 0.00026 & 0.00028 \\
\hline & chan $37(150 \mathrm{keV})$ & 0.00023 & 0.00025 & 0.00024 & 0.00021 & 0.00026 & 0.00030 & 0.00032 & 0.00032 & 0.00031 & 0.00025 & 0.00027 \\
\hline & chan $50(200 \mathrm{keV})$ & 0.00022 & 0.00023 & 0.00022 & 0.00020 & 0.00025 & 0.00028 & 0.00031 & 0.00030 & 0.00028 & 0.00023 & 0.00025 \\
\hline & chanl $62(250 \mathrm{keV})$ & 0.00020 & 0.00021 & 0.00021 & 0.00020 & 0.00024 & 0.00027 & 0.00030 & 0.00029 & 0.00027 & 0.00022 & 0.00024 \\
\hline & chan $75(300 \mathrm{keV})$ & 0.00019 & 0.00020 & 0.00020 & 0.00020 & 0.00023 & 0.00026 & 0.00028 & 0.00028 & 0.00026 & 0.00021 & 0.00022 \\
\hline & chan $87(350 \mathrm{keV})$ & 0.00018 & 0.00019 & 0.00018 & 0.00019 & 0.00022 & 0.00024 & 0.00027 & 0.00026 & 0.00024 & 0.00020 & 0.00021 \\
\hline & chan $100(400 \mathrm{keV})$ & 0.00017 & 0.00018 & 0.00017 & 0.00019 & 0.00021 & 0.00024 & 0.00026 & 0.00025 & 0.00022 & 0.00019 & 0.00020 \\
\hline & diff no cut & & & & $-23 \%$ & $-6 \%$ & $13 \%$ & $30 \%$ & $28 \%$ & $27 \%$ & $6 \%$ & $9 \%$ \\
\hline & diff $80 \mathrm{keV}$ cut & & & & $-19 \%$ & $0 \%$ & $16 \%$ & $29 \%$ & $31 \%$ & $28 \%$ & $3 \%$ & $8 \%$ \\
\hline & diff $100 \mathrm{keV}$ cut & & & & $-18 \%$ & $1 \%$ & $19 \%$ & $30 \%$ & $32 \%$ & $27 \%$ & $4 \%$ & $9 \%$ \\
\hline & diff $120 \mathrm{keV}$ cut & & & & $-15 \%$ & $4 \%$ & $22 \%$ & $32 \%$ & $32 \%$ & $28 \%$ & $4 \%$ & $10 \%$ \\
\hline & diff $150 \mathrm{keV}$ cut & & & & $-13 \%$ & $7 \%$ & $25 \%$ & $34 \%$ & $34 \%$ & $28 \%$ & $4 \%$ & $11 \%$ \\
\hline & diff $200 \mathrm{keV}$ cut & & & & $-9 \%$ & $10 \%$ & $26 \%$ & $37 \%$ & $35 \%$ & $27 \%$ & $5 \%$ & $12 \%$ \\
\hline & diff $250 \mathrm{keV}$ cut & & & & $-4 \%$ & $14 \%$ & $28 \%$ & $42 \%$ & $37 \%$ & $30 \%$ & $6 \%$ & $14 \%$ \\
\hline & diff $300 \mathrm{keV}$ cut & & & & $1 \%$ & $18 \%$ & $32 \%$ & $43 \%$ & $40 \%$ & $30 \%$ & $7 \%$ & $14 \%$ \\
\hline & diff $350 \mathrm{keV}$ cut & & & & $5 \%$ & $21 \%$ & $33 \%$ & $48 \%$ & $41 \%$ & $33 \%$ & $6 \%$ & $14 \%$ \\
\hline & diff $400 \mathrm{keV}$ cut & & & & $9 \%$ & $25 \%$ & $38 \%$ & $53 \%$ & $44 \%$ & $29 \%$ & $9 \%$ & $16 \%$ \\
\hline
\end{tabular}

Page 33 of 43 


\begin{tabular}{|c|c|c|c|c|c|c|c|c|c|c|c|c|}
\hline \multicolumn{2}{|c|}{ source to poly distance } & $\begin{array}{c}\text { Exp Tube } \\
1\end{array}$ & $\begin{array}{c}\text { Exp Tube } \\
2\end{array}$ & $\begin{array}{c}\text { Exp } \\
\text { Average }\end{array}$ & $\begin{array}{c}\text { model: } \\
0.5\end{array}$ & $\begin{array}{c}\text { model: } \\
0.75\end{array}$ & $\begin{array}{c}\text { model: } \\
1\end{array}$ & $\begin{array}{c}\text { model: } \\
2 \\
\end{array}$ & $\begin{array}{c}\text { model: } \\
2.5\end{array}$ & $\begin{array}{c}\text { model: } \\
\mathbf{3} \\
\end{array}$ & $\begin{array}{c}\text { model: } \\
4\end{array}$ & $\begin{array}{c}\text { model: } \\
5\end{array}$ \\
\hline \multirow{21}{*}{$\begin{array}{l}100 \\
\mathrm{~cm}\end{array}$} & & & & & & & & & & & & \\
\hline & no cut & 0.00009 & 0.00009 & 0.00009 & 0.00008 & 0.00009 & 0.00011 & 0.00012 & 0.00012 & 0.00013 & 0.00010 & 0.00008 \\
\hline & chan $20(80 \mathrm{keV})$ & 0.00008 & 0.00008 & 0.00008 & 0.00006 & 0.00009 & 0.00011 & 0.00011 & 0.00011 & 0.00011 & 0.00008 & 0.00007 \\
\hline & chan $25(100 \mathrm{keV})$ & 0.00008 & 0.00008 & 0.00008 & 0.00006 & 0.00009 & 0.00010 & 0.00011 & 0.00011 & 0.00010 & 0.00008 & 0.00007 \\
\hline & chan $30(120 \mathrm{keV})$ & 0.00008 & 0.00008 & 0.00008 & 0.00006 & 0.00009 & 0.00010 & 0.00011 & 0.00011 & 0.00010 & 0.00008 & 0.00007 \\
\hline & chan $37(150 \mathrm{keV})$ & 0.00007 & 0.00008 & 0.00008 & 0.00006 & 0.00009 & 0.00010 & 0.00011 & 0.00010 & 0.00010 & 0.00008 & 0.00006 \\
\hline & chan $50(200 \mathrm{keV})$ & 0.00007 & 0.00007 & 0.00007 & 0.00006 & 0.00009 & 0.00010 & 0.00010 & 0.00010 & 0.00009 & 0.00007 & 0.00006 \\
\hline & chanl $62(250 \mathrm{keV})$ & 0.00006 & 0.00007 & 0.00007 & 0.00006 & 0.00008 & 0.00009 & 0.00010 & 0.00009 & 0.00008 & 0.00007 & 0.00006 \\
\hline & chan $75(300 \mathrm{keV})$ & 0.00006 & 0.00007 & 0.00006 & 0.00006 & 0.00008 & 0.00009 & 0.00009 & 0.00009 & 0.00008 & 0.00006 & 0.00006 \\
\hline & chan $87(350 \mathrm{keV})$ & 0.00006 & 0.00006 & 0.00006 & 0.00006 & 0.00008 & 0.00009 & 0.00009 & 0.00008 & 0.00007 & 0.00006 & 0.00006 \\
\hline & chan $100(400 \mathrm{keV})$ & 0.00005 & 0.00006 & 0.00005 & 0.00005 & 0.00007 & 0.00008 & 0.00008 & 0.00008 & 0.00007 & 0.00006 & 0.00005 \\
\hline & diff no cut & & & & $-14 \%$ & $2 \%$ & $21 \%$ & $36 \%$ & $35 \%$ & $37 \%$ & $4 \%$ & $-13 \%$ \\
\hline & diff $80 \mathrm{keV}$ cut & & & & $-29 \%$ & $8 \%$ & $27 \%$ & $36 \%$ & $32 \%$ & $33 \%$ & $-2 \%$ & $-15 \%$ \\
\hline & diff $100 \mathrm{keV}$ cut & & & & $-29 \%$ & $9 \%$ & $28 \%$ & $36 \%$ & $29 \%$ & $27 \%$ & $-4 \%$ & $-17 \%$ \\
\hline & diff $120 \mathrm{keV}$ cut & & & & $-26 \%$ & $15 \%$ & $33 \%$ & $41 \%$ & $34 \%$ & $28 \%$ & $-1 \%$ & $-17 \%$ \\
\hline & diff $150 \mathrm{keV}$ cut & & & & $-23 \%$ & $18 \%$ & $36 \%$ & $45 \%$ & $36 \%$ & $29 \%$ & $0 \%$ & $-15 \%$ \\
\hline & diff $200 \mathrm{keV}$ cut & & & & $-18 \%$ & $22 \%$ & $39 \%$ & $45 \%$ & $36 \%$ & $24 \%$ & $-4 \%$ & $-16 \%$ \\
\hline & diff $250 \mathrm{keV}$ cut & & & & $-16 \%$ & $23 \%$ & $42 \%$ & $48 \%$ & $35 \%$ & $25 \%$ & $-1 \%$ & $-14 \%$ \\
\hline & diff $300 \mathrm{keV}$ cut & & & & $-11 \%$ & $27 \%$ & $45 \%$ & $49 \%$ & $40 \%$ & $24 \%$ & $2 \%$ & $-11 \%$ \\
\hline & diff $350 \mathrm{keV}$ cut & & & & $-5 \%$ & $30 \%$ & $45 \%$ & $50 \%$ & $42 \%$ & $27 \%$ & $3 \%$ & $-6 \%$ \\
\hline & diff $400 \mathrm{keV}$ cut & & & & $-3 \%$ & $33 \%$ & $48 \%$ & $53 \%$ & $41 \%$ & $25 \%$ & $7 \%$ & $-6 \%$ \\
\hline \multirow{21}{*}{$\begin{array}{l}200 \\
\mathrm{~cm}\end{array}$} & & & & & & & & & & & & \\
\hline & no cut & 0.00003 & 0.00003 & 0.00003 & 0.00003 & 0.00004 & 0.00004 & 0.00005 & 0.00004 & 0.00005 & 0.00003 & 0.00003 \\
\hline & chan $20(80 \mathrm{keV})$ & 0.00003 & 0.00003 & 0.00003 & 0.00003 & 0.00003 & 0.00004 & 0.00005 & 0.00004 & 0.00004 & 0.00003 & 0.00003 \\
\hline & chan $25(100 \mathrm{keV})$ & 0.00002 & 0.00003 & 0.00003 & 0.00003 & 0.00003 & 0.00004 & 0.00005 & 0.00004 & 0.00004 & 0.00003 & 0.00003 \\
\hline & chan $30(120 \mathrm{keV})$ & 0.00002 & 0.00003 & 0.00003 & 0.00003 & 0.00003 & 0.00004 & 0.00004 & 0.00004 & 0.00004 & 0.00003 & 0.00003 \\
\hline & chan $37(150 \mathrm{keV})$ & 0.00002 & 0.00003 & 0.00002 & 0.00003 & 0.00003 & 0.00004 & 0.00004 & 0.00004 & 0.00004 & 0.00003 & 0.00003 \\
\hline & chan $50(200 \mathrm{keV})$ & 0.00002 & 0.00003 & 0.00002 & 0.00003 & 0.00003 & 0.00004 & 0.00004 & 0.00004 & 0.00004 & 0.00003 & 0.00002 \\
\hline & chanl $62(250 \mathrm{keV})$ & 0.00002 & 0.00002 & 0.00002 & 0.00002 & 0.00003 & 0.00003 & 0.00004 & 0.00004 & 0.00004 & 0.00003 & 0.00002 \\
\hline & chan $75(300 \mathrm{keV})$ & 0.00002 & 0.00002 & 0.00002 & 0.00002 & 0.00003 & 0.00003 & 0.00004 & 0.00003 & 0.00003 & 0.00002 & 0.00002 \\
\hline & chan $87(350 \mathrm{keV})$ & 0.00002 & 0.00002 & 0.00002 & 0.00002 & 0.00003 & 0.00003 & 0.00004 & 0.00003 & 0.00003 & 0.00002 & 0.00002 \\
\hline & chan $100(400 \mathrm{keV})$ & 0.00002 & 0.00002 & 0.00002 & 0.00002 & 0.00003 & 0.00003 & 0.00004 & 0.00003 & 0.00003 & 0.00002 & 0.00002 \\
\hline & diff no cut & & & & $-6 \%$ & $22 \%$ & $37 \%$ & $60 \%$ & $49 \%$ & $53 \%$ & $13 \%$ & $0 \%$ \\
\hline & diff $80 \mathrm{keV}$ cut & & & & $2 \%$ & $29 \%$ & $44 \%$ & $73 \%$ & $50 \%$ & $62 \%$ & $14 \%$ & $0 \%$ \\
\hline & diff $100 \mathrm{keV}$ cut & & & & $4 \%$ & $32 \%$ & $47 \%$ & $74 \%$ & $50 \%$ & $55 \%$ & $13 \%$ & $0 \%$ \\
\hline & diff $120 \mathrm{keV}$ cut & & & & $4 \%$ & $34 \%$ & $50 \%$ & $78 \%$ & $53 \%$ & $62 \%$ & $12 \%$ & $4 \%$ \\
\hline & diff $150 \mathrm{keV}$ cut & & & & $6 \%$ & $35 \%$ & $53 \%$ & $85 \%$ & $57 \%$ & $65 \%$ & $17 \%$ & $6 \%$ \\
\hline & diff $200 \mathrm{keV}$ cut & & & & $12 \%$ & $44 \%$ & $55 \%$ & $94 \%$ & $58 \%$ & $66 \%$ & $25 \%$ & $10 \%$ \\
\hline & diff $250 \mathrm{keV}$ cut & & & & $14 \%$ & $50 \%$ & $60 \%$ & $99 \%$ & $64 \%$ & $67 \%$ & $25 \%$ & $13 \%$ \\
\hline & diff $300 \mathrm{keV}$ cut & & & & $21 \%$ & $57 \%$ & $68 \%$ & $102 \%$ & $67 \%$ & $66 \%$ & $21 \%$ & $16 \%$ \\
\hline & diff $350 \mathrm{keV}$ cut & & & & $27 \%$ & $66 \%$ & $75 \%$ & $112 \%$ & $62 \%$ & $76 \%$ & $20 \%$ & $15 \%$ \\
\hline & diff $400 \mathrm{keV}$ cut & & & & $36 \%$ & $66 \%$ & $87 \%$ & $116 \%$ & $72 \%$ & $87 \%$ & $26 \%$ & $20 \%$ \\
\hline
\end{tabular}

Page 34 of 43 
Table 9.2 provides detailed results of the modeling of an individual boron-lined tube in a polyethylene moderator assuming either a boron nitride or boron carbide lining, as discussed in Section 3, and their comparison to experimental results. The first set of rows for each distance is the $\mathrm{BN}$ results, and the second set of rows is the $\mathrm{B}_{4} \mathrm{C}$ results. Note that not all of the thicknesses were simulated for the $\mathrm{B}_{4} \mathrm{C}$ lining. The first column of the table gives the distance between the source and the front of the moderator (only 50 and $100 \mathrm{~cm}$ were modeled). The second column provides the energy threshold ("cuts" in keV) used for each row of the table. The next several pairs of columns provide the model results and a comparison to the experimental results, where the number is the thickness of the boron lining in micrometers and the percent difference is between model and experiment (model minus experiment divided by experiment). A positive number indicates the model overestimates the response. It is seen that the best consistent agreement is found for a lining thickness of $2 \mu \mathrm{m}$ of $\mathrm{BN}$, though agreement is similar for aligning thickness of $1.5 \mu \mathrm{m}$ of $\mathrm{BN}$. For $\mathrm{B}_{4} \mathrm{C}$ the best agreement between the simulated and measured results is achieved with a $1 \mu \mathrm{m}$ lining. 
Table 9.2. Moderated single tube results using $\mathrm{BN}$ and $\mathrm{B}_{4} \mathrm{C}$ linings.

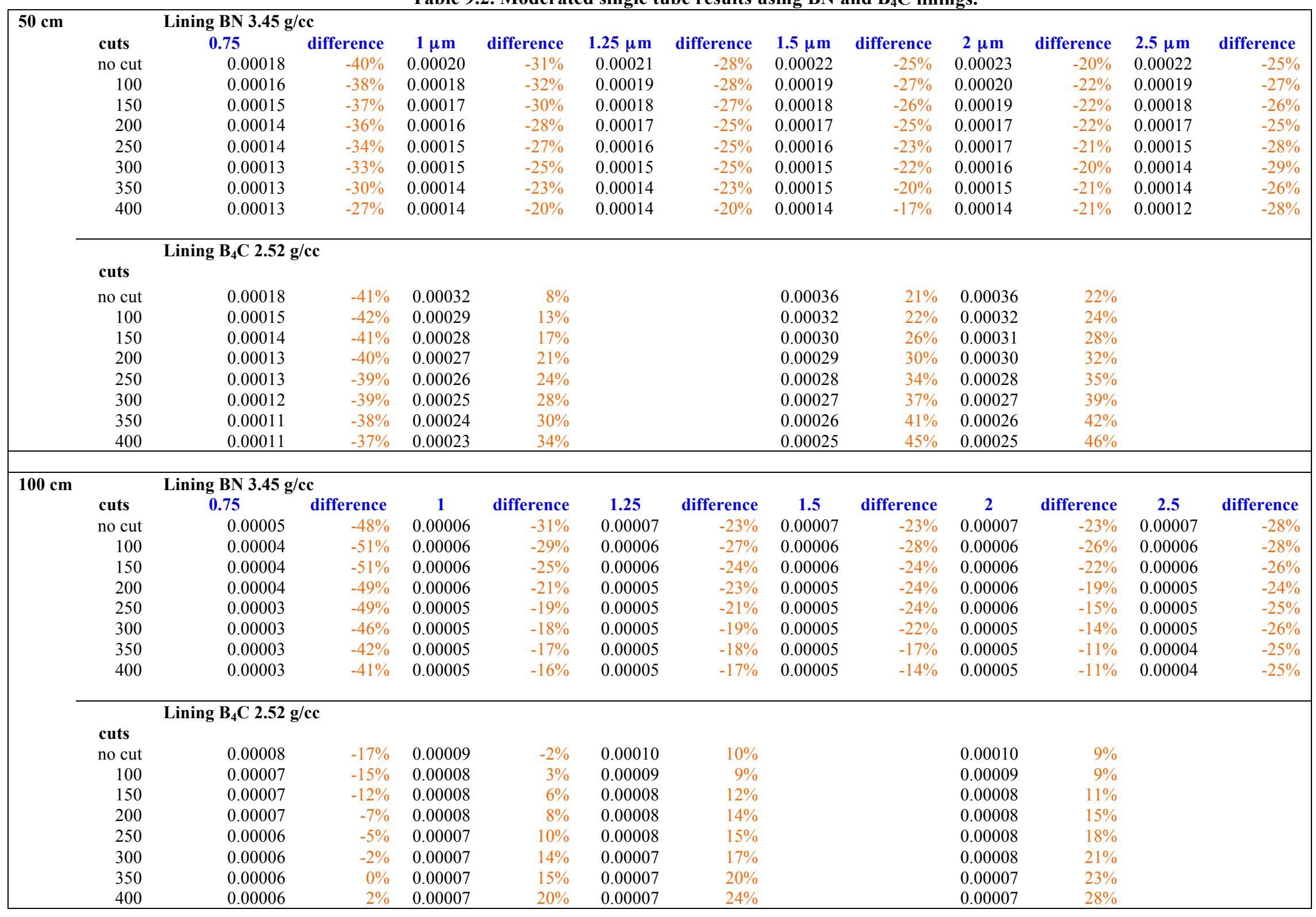

Page 36 of 43 
Some of the results of the models compared to the experimental measurements for the moderated boron lined tubes are summarized in Table 9.3. The experimental values listed are counts per neutron emitted from the source (which have been scaled up by a factor of $10^{4}$ ). Different lower energy cutoffs (LEC) were applied to both the experimental and simulated results. The values shown for the models are the percent difference between model and experiment (a positive value indicates the model value is larger than the experimental value). Model results are shown for various boron thicknesses (pure ${ }^{10} \mathrm{~B}$ ) from 0.5 to $5 \mu \mathrm{m}$. The most consistent agreement is seen for the thicknesses of 0.75 and $4 \mu \mathrm{m}$ for the nearer distances. Agreement between model and experiment is worse at larger distances (such as $2 \mathrm{~m}$ ) and thus may be due to scattering effects not captured in the model being more important at larger distances. 
Table 9.3. Results of simulations compared to measurements for moderated individual tubes.

\begin{tabular}{|c|c|c|c|c|c|c|c|c|c|}
\hline & LEC $(\mathrm{MeV})==>$ & 0.050 & 0.100 & 0.150 & 0.200 & 0.250 & 0.300 & 0.350 & 0.400 \\
\hline \begin{tabular}{|l|} 
Source \\
Position \\
\end{tabular} & Lining Thickness $(\mu \mathrm{m})$ & & & & & & & & \\
\hline \multirow[t]{8}{*}{$2 \mathrm{~m}$} & Measured Average $\left(\mathrm{x}^{2} 0^{4}\right)==>$ & 0.270 & 0.264 & 0.242 & 0.227 & 0.215 & 0.202 & 0.188 & 0.176 \\
\hline & 0.50 & $2 \%$ & $4 \%$ & $6 \%$ & $12 \%$ & $14 \%$ & $21 \%$ & $27 \%$ & $36 \%$ \\
\hline & 0.75 & $32 \%$ & $32 \%$ & $29 \%$ & $44 \%$ & $50 \%$ & $57 \%$ & $66 \%$ & $66 \%$ \\
\hline & 1.00 & $45 \%$ & $47 \%$ & $46 \%$ & $55 \%$ & $60 \%$ & $68 \%$ & $75 \%$ & $87 \%$ \\
\hline & 2.00 & $73 \%$ & $74 \%$ & $78 \%$ & $94 \%$ & $99 \%$ & $102 \%$ & $112 \%$ & $116 \%$ \\
\hline & 3.00 & $62 \%$ & $55 \%$ & $58 \%$ & $66 \%$ & $67 \%$ & $66 \%$ & $76 \%$ & $87 \%$ \\
\hline & 4.00 & $21 \%$ & $13 \%$ & $12 \%$ & $25 \%$ & $25 \%$ & $21 \%$ & $20 \%$ & $26 \%$ \\
\hline & 5.00 & $5 \%$ & $0 \%$ & $2 \%$ & $10 \%$ & $13 \%$ & $16 \%$ & $15 \%$ & $20 \%$ \\
\hline \multirow[t]{8}{*}{$1 \mathrm{~m}$} & Measured $\left(\mathbf{x 1 0}^{4}\right)==>$ & 0.831 & 0.805 & 0.751 & 0.706 & 0.669 & 0.626 & 0.588 & 0.545 \\
\hline & 0.50 & -29 & $-29 \%$ & $-23 \%$ & $-18 \%$ & $-16 \%$ & $-11 \%$ & $-5 \%$ & $-3 \%$ \\
\hline & 0.75 & $6 \%$ & $12 \%$ & $18 \%$ & $22 \%$ & $23 \%$ & $27 \%$ & $30 \%$ & $33 \%$ \\
\hline & 1.00 & $24 \%$ & $30 \%$ & $36 \%$ & $39 \%$ & $42 \%$ & $45 \%$ & $45 \%$ & $48 \%$ \\
\hline & 2.00 & $36 \%$ & $39 \%$ & $45 \%$ & $45 \%$ & $48 \%$ & $49 \%$ & $50 \%$ & $53 \%$ \\
\hline & 3.00 & $33 \%$ & $27 \%$ & $29 \%$ & $24 \%$ & $25 \%$ & $24 \%$ & $27 \%$ & $25 \%$ \\
\hline & 4.00 & $-2 \%$ & $-4 \%$ & $0 \%$ & $-4 \%$ & $-1 \%$ & $2 \%$ & $3 \%$ & $7 \%$ \\
\hline & 5.00 & $-15 \%$ & $-17 \%$ & $-15 \%$ & $-16 \%$ & $-14 \%$ & $-11 \%$ & $-6 \%$ & $-6 \%$ \\
\hline \multirow[t]{8}{*}{$0.5 \mathrm{~m}$} & Measured $\left(\mathrm{x}^{10^{4}}\right)==>$ & 2.661 & 2.585 & 2.401 & 2.235 & 2.094 & 1.961 & 1.842 & 1.717 \\
\hline & 0.50 & $-19 \%$ & $-18 \%$ & $-13 \%$ & $-9 \%$ & $-4 \%$ & $1 \%$ & $5 \%$ & $9 \%$ \\
\hline & 0.75 & $0 \%$ & $1 \%$ & $7 \%$ & $10 \%$ & $14 \%$ & $18 \%$ & $21 \%$ & $25 \%$ \\
\hline & 1.00 & $16 \%$ & $19 \%$ & $25 \%$ & $26 \%$ & $28 \%$ & $32 \%$ & $33 \%$ & $38 \%$ \\
\hline & 2.00 & $29 \%$ & $30 \%$ & $34 \%$ & $35 \%$ & $37 \%$ & $40 \%$ & $41 \%$ & $44 \%$ \\
\hline & 3.00 & $28 \%$ & $27 \%$ & $28 \%$ & $27 \%$ & $30 \%$ & $30 \%$ & $33 \%$ & $29 \%$ \\
\hline & 4.00 & $3 \%$ & $4 \%$ & $4 \%$ & $5 \%$ & $6 \%$ & $7 \%$ & $6 \%$ & $9 \%$ \\
\hline & 5.00 & $8 \%$ & $9 \%$ & $11 \%$ & $12 \%$ & $14 \%$ & $14 \%$ & $14 \%$ & $16 \%$ \\
\hline
\end{tabular}




\begin{tabular}{|c|c|c|c|c|c|c|c|c|c|}
\hline \multicolumn{2}{|r|}{ LEC $(\mathrm{MeV})==>$} & \multirow[t]{2}{*}{0.050} & \multirow[t]{2}{*}{0.100} & \multirow[t]{2}{*}{0.150} & \multirow[t]{2}{*}{0.200} & \multirow[t]{2}{*}{0.250} & \multirow[t]{2}{*}{0.300} & \multirow[t]{2}{*}{0.350} & \multirow[t]{2}{*}{0.400} \\
\hline \begin{tabular}{|l|} 
Source \\
Position
\end{tabular} & Lining Thickness $(\mu \mathrm{m})$ & & & & & & & & \\
\hline \multirow[t]{8}{*}{$0.25 \mathrm{~m}$} & Measured $\left(x 10^{4}\right)==>$ & 6.784 & 6.595 & 6.171 & 5.776 & 5.427 & 5.089 & 4.784 & 4.459 \\
\hline & 0.50 & $-20 \%$ & $-18 \%$ & $-13 \%$ & $-10 \%$ & $-5 \%$ & $-1 \%$ & $3 \%$ & $8 \%$ \\
\hline & 0.75 & $0 \%$ & $2 \%$ & $6 \%$ & $9 \%$ & $12 \%$ & $16 \%$ & $18 \%$ & $21 \%$ \\
\hline & 1.00 & $13 \%$ & $14 \%$ & $17 \%$ & $19 \%$ & $23 \%$ & $26 \%$ & $29 \%$ & $33 \%$ \\
\hline & 2.00 & $32 \%$ & $33 \%$ & $34 \%$ & $37 \%$ & $41 \%$ & $44 \%$ & $48 \%$ & $52 \%$ \\
\hline & 3.00 & $29 \%$ & $30 \%$ & $31 \%$ & $32 \%$ & $34 \%$ & $37 \%$ & $38 \%$ & $39 \%$ \\
\hline & 4.00 & $0 \%$ & $0 \%$ & $0 \%$ & $0 \%$ & $0 \%$ & $2 \%$ & $2 \%$ & $2 \%$ \\
\hline & 5.00 & $-14 \%$ & $-14 \%$ & $-14 \%$ & $-15 \%$ & $-15 \%$ & $-13 \%$ & $-12 \%$ & $-12 \%$ \\
\hline \multirow[t]{8}{*}{$0.1 \mathrm{~m}$} & 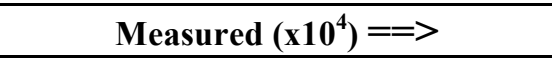 & 17.56 & 17.08 & 15.92 & 14.90 & 14.01 & 13.11 & 12.31 & 11.44 \\
\hline & 0.50 & $-23 \%$ & $-22 \%$ & $-17 \%$ & $-13 \%$ & $-9 \%$ & $-5 \%$ & $0 \%$ & $4 \%$ \\
\hline & 0.75 & $-2 \%$ & $0 \%$ & $5 \%$ & $8 \%$ & $13 \%$ & $17 \%$ & $19 \%$ & $22 \%$ \\
\hline & 1.00 & $14 \%$ & $15 \%$ & $19 \%$ & $22 \%$ & $26 \%$ & $29 \%$ & $33 \%$ & $36 \%$ \\
\hline & 2.00 & $25 \%$ & $25 \%$ & $28 \%$ & $31 \%$ & $35 \%$ & $39 \%$ & $42 \%$ & $46 \%$ \\
\hline & 3.00 & $14 \%$ & $15 \%$ & $16 \%$ & $20 \%$ & $22 \%$ & $23 \%$ & $24 \%$ & $25 \%$ \\
\hline & 4.00 & $-1 \%$ & $-2 \%$ & $-1 \%$ & $0 \%$ & $1 \%$ & $2 \%$ & $4 \%$ & $5 \%$ \\
\hline & 5.00 & $-14 \%$ & $-14 \%$ & $-13 \%$ & $-11 \%$ & $-10 \%$ & $-9 \%$ & $-8 \%$ & $-7 \%$ \\
\hline
\end{tabular}

The ${ }^{10} \mathrm{~B}$ that is coated on the inside of the tubes may be a compound rather than metal, so an organic constituent was added to the lining composition in the model to represent this. The exact lining composition is not known, as it is proprietary, so nitrogen was chosen to represent the organic component of the lining, in the form of boron nitride. Table 9.4 provides detailed results of the modeling of an individual boronlined tube in a polyethylene moderator assuming a boron nitride lining, as discussed in Section 3, and comparison to experiment. Results are given for various low energy cutoff values and different lining thicknesses. 
Table 9.4. Results of simulations compared to measurements for moderated individual tubes.

\begin{tabular}{|c|c|c|c|c|c|c|c|c|c|}
\hline & LEC $(\mathrm{MeV})==>$ & 0.050 & 0.100 & 0.150 & 0.200 & 0.250 & 0.300 & 0.350 & 0.400 \\
\hline Source Position & Lining Thickness $(\mu \mathrm{m})$ & & & & & & & & \\
\hline \multicolumn{10}{|c|}{$1 \mathrm{~m}$ - boron metal lining $(2.34 \mathrm{~g} / \mathrm{cc})$} \\
\hline & 0.75 & $6 \%$ & $12 \%$ & $18 \%$ & $22 \%$ & $23 \%$ & $27 \%$ & $30 \%$ & $33 \%$ \\
\hline & 1.00 & $24 \%$ & $30 \%$ & $36 \%$ & $39 \%$ & $42 \%$ & $45 \%$ & $45 \%$ & $48 \%$ \\
\hline & 1.25 & $43 \%$ & $44 \%$ & $44 \%$ & $46 \%$ & $50 \%$ & $55 \%$ & $53 \%$ & $59 \%$ \\
\hline & 2.00 & $36 \%$ & $39 \%$ & $45 \%$ & $45 \%$ & $48 \%$ & $49 \%$ & $50 \%$ & $53 \%$ \\
\hline \multicolumn{10}{|c|}{$1 \mathrm{~m}-\mathrm{BN}$ lining $(3.45 \mathrm{~g} / \mathrm{cc})$} \\
\hline & 0.75 & $-52 \%$ & $-51 \%$ & $-51 \%$ & $-49 \%$ & $-49 \%$ & $-46 \%$ & $-42 \%$ & $-41 \%$ \\
\hline & 1.00 & $-31 \%$ & $-29 \%$ & $-25 \%$ & $-21 \%$ & $-19 \%$ & $-18 \%$ & $-17 \%$ & $-16 \%$ \\
\hline & 1.25 & $-27 \%$ & $-27 \%$ & $-24 \%$ & $-23 \%$ & $-21 \%$ & $-19 \%$ & $-18 \%$ & $-17 \%$ \\
\hline & 2.00 & $-26 \%$ & $-27 \%$ & $-22 \%$ & $-19 \%$ & $-15 \%$ & $-14 \%$ & $-11 \%$ & $-11 \%$ \\
\hline \multicolumn{10}{|c|}{$1 \mathrm{~m}-\mathrm{B}_{4} \mathrm{C}$ lining $(2.52 \mathrm{~g} / \mathrm{cc})$} \\
\hline & 0.75 & $-17 \%$ & $-15 \%$ & $-12 \%$ & $-7 \%$ & $-5 \%$ & $-2 \%$ & $0 \%$ & $2 \%$ \\
\hline & 1.00 & $0 \%$ & $2 \%$ & $6 \%$ & $8 \%$ & $10 \%$ & $14 \%$ & $15 \%$ & $20 \%$ \\
\hline & 1.25 & $8 \%$ & $9 \%$ & $12 \%$ & $14 \%$ & $15 \%$ & $17 \%$ & $20 \%$ & $24 \%$ \\
\hline & 2.00 & $8 \%$ & $9 \%$ & $11 \%$ & $15 \%$ & $18 \%$ & $21 \%$ & $23 \%$ & $28 \%$ \\
\hline \multicolumn{10}{|c|}{$0.5 \mathrm{~m}-$ boron metal lining $(2.34 \mathrm{~g} / \mathrm{cc})$} \\
\hline & 0.75 & $0 \%$ & $1 \%$ & $7 \%$ & $10 \%$ & $14 \%$ & $18 \%$ & $21 \%$ & $25 \%$ \\
\hline & 1.00 & $16 \%$ & $19 \%$ & $25 \%$ & $26 \%$ & $28 \%$ & $32 \%$ & $33 \%$ & $38 \%$ \\
\hline & 1.25 & $25 \%$ & $25 \%$ & $29 \%$ & $33 \%$ & $36 \%$ & $42 \%$ & $45 \%$ & $48 \%$ \\
\hline & 2.00 & $29 \%$ & $30 \%$ & $34 \%$ & $37 \%$ & $42 \%$ & $43 \%$ & $48 \%$ & $53 \%$ \\
\hline \multicolumn{10}{|c|}{$0.5 \mathrm{~m}-\mathrm{BN}$ lining $(3.45 \mathrm{~g} / \mathrm{cc})$} \\
\hline & 0.75 & $-37 \%$ & $-38 \%$ & $-37 \%$ & $-36 \%$ & $-34 \%$ & $-33 \%$ & $-30 \%$ & $-27 \%$ \\
\hline & 1.00 & $-30 \%$ & $-32 \%$ & $-30 \%$ & $-28 \%$ & $-27 \%$ & $-25 \%$ & $-23 \%$ & $-20 \%$ \\
\hline & 1.25 & $-26 \%$ & $-28 \%$ & $-27 \%$ & $-25 \%$ & $-25 \%$ & $-25 \%$ & $-23 \%$ & $-20 \%$ \\
\hline & 2.00 & $-19 \%$ & $-22 \%$ & $-22 \%$ & $-22 \%$ & $-20 \%$ & $-20 \%$ & $-21 \%$ & $-21 \%$ \\
\hline \multicolumn{10}{|c|}{$0.5 \mathrm{~m}-\mathrm{B}_{4} \mathrm{C}$ lining $(2.52 \mathrm{~g} / \mathrm{cc})$} \\
\hline & 0.75 & $-39 \%$ & $-42 \%$ & $-41 \%$ & $-40 \%$ & $-39 \%$ & $-39 \%$ & $-38 \%$ & $-37 \%$ \\
\hline & 1.00 & $-6 \%$ & $-4 \%$ & $17 \%$ & $21 \%$ & $24 \%$ & $28 \%$ & $30 \%$ & $34 \%$ \\
\hline & 1.25 & $1 \%$ & $2 \%$ & $5 \%$ & $8 \%$ & $11 \%$ & $14 \%$ & $17 \%$ & $21 \%$ \\
\hline & 2.00 & $23 \%$ & $24 \%$ & $28 \%$ & $32 \%$ & $35 \%$ & $39 \%$ & $42 \%$ & $46 \%$ \\
\hline
\end{tabular}




\section{Appendix C: Complete set of Modeled Multiple Tube Panel Results}

Table 10.1 provides detailed results of the modeling of the multiple tube system, as discussed in Section 4, and comparison to experiment.

Listed in the table are the results for different boron metal lined thicknesses (rows) and lower-energy cut off (LEC) values (columns). The boron density was $2.34 \mathrm{~g} / \mathrm{cc}$. The experimental values are counts per emitted neutron (multiplied by 100). The values shown for the models are the percent difference between model and experiment (a positive value indicates the model value is larger than the experimental value). Except for the $1 \mathrm{~m}$ Front Midpoint set, there are three rows of results showing the changes over the range of boron-lined thickness values from 0.75 $\mu \mathrm{m}$ to $1.25 \mu \mathrm{m}$. For the $1 \mathrm{~m}$ Front Midpoint set, the range of boron-lined thickness was extended to $2 \mu \mathrm{m}$, which showed that the peak of efficiency for the solid ${ }^{10} \mathrm{~B}$ composition had been attained with $1.25 \mu \mathrm{m}$. 
Table 10.1. Model compared to experiment efficiency as a function of boron metal thickness and low-energy cutoff.

\begin{tabular}{|c|c|c|c|c|c|c|c|c|c|}
\hline & LEC $(\mathrm{MeV})==>$ & 0.050 & 0.100 & 0.150 & 0.200 & 0.250 & 0.300 & 0.350 & 0.400 \\
\hline Source Position & Lining Thickness (mm) & & & & & & & & \\
\hline \multirow[t]{4}{*}{ Front 2 m Midpoint } & Measured $(x 100)==>$ & 0.130 & 0.123 & 0.115 & 0.109 & 0.103 & 0.097 & 0.092 & 0.086 \\
\hline & 0.75 & $14 \%$ & $17 \%$ & $21 \%$ & $24 \%$ & $26 \%$ & $24 \%$ & $24 \%$ & $25 \%$ \\
\hline & 1.00 & $22 \%$ & $24 \%$ & $27 \%$ & $28 \%$ & $29 \%$ & $28 \%$ & $29 \%$ & $31 \%$ \\
\hline & 1.25 & $24 \%$ & $24 \%$ & $27 \%$ & $27 \%$ & $29 \%$ & $27 \%$ & $28 \%$ & $29 \%$ \\
\hline \multirow[t]{6}{*}{ Front $1 \mathrm{~m}$ Midpoint } & Measured $(x 100)==>$ & 0.352 & 0.331 & 0.312 & 0.294 & 0.278 & 0.264 & 0.248 & 0.234 \\
\hline & 0.75 & $22 \%$ & $26 \%$ & $30 \%$ & $33 \%$ & $35 \%$ & $32 \%$ & $33 \%$ & $33 \%$ \\
\hline & 1.00 & $30 \%$ & $33 \%$ & $35 \%$ & $37 \%$ & $38 \%$ & $36 \%$ & $38 \%$ & $38 \%$ \\
\hline & 1.25 & $32 \%$ & $33 \%$ & $35 \%$ & $36 \%$ & $38 \%$ & $35 \%$ & $37 \%$ & $38 \%$ \\
\hline & 1.50 & $30 \%$ & $31 \%$ & $33 \%$ & $35 \%$ & $36 \%$ & $33 \%$ & $35 \%$ & $36 \%$ \\
\hline & 2.00 & $23 \%$ & $24 \%$ & $26 \%$ & $28 \%$ & $29 \%$ & $26 \%$ & $28 \%$ & $28 \%$ \\
\hline \multirow[t]{4}{*}{ Front $1 \mathrm{~m}$ Right End } & Measured $(x 100)==>$ & 0.225 & 0.212 & 0.200 & 0.189 & 0.179 & 0.169 & 0.159 & 0.150 \\
\hline & 0.75 & $23 \%$ & $27 \%$ & $31 \%$ & $33 \%$ & $36 \%$ & $33 \%$ & $34 \%$ & $34 \%$ \\
\hline & 1.00 & $32 \%$ & $34 \%$ & $37 \%$ & $38 \%$ & $39 \%$ & $38 \%$ & $39 \%$ & $40 \%$ \\
\hline & 1.25 & $33 \%$ & $35 \%$ & $36 \%$ & $37 \%$ & $38 \%$ & $36 \%$ & $38 \%$ & $39 \%$ \\
\hline \multirow[t]{4}{*}{ Front $1 \mathrm{~m}$ Left End } & Measured $(x 100)==>$ & 0.209 & 0.197 & 0.186 & 0.175 & 0.166 & 0.157 & 0.148 & 0.139 \\
\hline & 0.75 & $29 \%$ & $33 \%$ & $36 \%$ & $40 \%$ & $42 \%$ & $39 \%$ & $40 \%$ & $40 \%$ \\
\hline & 1.00 & $38 \%$ & $40 \%$ & $42 \%$ & $45 \%$ & $45 \%$ & $44 \%$ & $45 \%$ & $46 \%$ \\
\hline & 1.25 & $39 \%$ & $41 \%$ & $42 \%$ & $44 \%$ & $45 \%$ & $42 \%$ & $44 \%$ & $46 \%$ \\
\hline \multirow[t]{4}{*}{ Back 1 m Midpoint } & Measured $(x 100)==>$ & 0.325 & 0.306 & 0.288 & 0.271 & 0.257 & 0.244 & 0.228 & 0.215 \\
\hline & 0.75 & $17 \%$ & $21 \%$ & $24 \%$ & $28 \%$ & $30 \%$ & $26 \%$ & $28 \%$ & $28 \%$ \\
\hline & 1.00 & $25 \%$ & $27 \%$ & $30 \%$ & $32 \%$ & $32 \%$ & $30 \%$ & $32 \%$ & $33 \%$ \\
\hline & 1.25 & $26 \%$ & $28 \%$ & $29 \%$ & $31 \%$ & $32 \%$ & $29 \%$ & $32 \%$ & $33 \%$ \\
\hline
\end{tabular}

Table 10.2 lists similar results that compare those for boron metal (repeat of Table 10.1), BN (density was $3.45 \mathrm{~g} / \mathrm{cc}$ ), and $\mathrm{B}_{4} \mathrm{C}$ (density was $2.52 \mathrm{~g} / \mathrm{cc})$.

The best agreement is seen for the $0.75 \mu \mathrm{m}$ thickness for the boron metal and $\mathrm{B}_{4} \mathrm{C}$ linings, and for the 1.0-1.5 $\mu \mathrm{m}$ thickness for the $\mathrm{BN}$ lining. For boron metal, the model tends to over predict experiment by $20-30 \%$ 
Table 10.2. Model compared to experiment efficiency as a function of boron lining material.

\begin{tabular}{|c|c|c|c|c|c|c|c|c|c|}
\hline & LEC $(\mathrm{MeV})==>$ & 0.050 & $\overline{0.100}$ & $\overline{0.150}$ & $\overline{0.200}$ & $\overline{0.250}$ & $\overline{0.300}$ & $\overline{0.350}$ & $\overline{0.400}$ \\
\hline Source Position & $\begin{array}{l}\text { Lining Thickness } \\
\text { (mm) }\end{array}$ & & & & & & & & \\
\hline \multicolumn{10}{|c|}{$\begin{array}{l}\text { Front } 1 \mathrm{~m} \\
\text { Midpoint - boron metal lining }(2.34 \mathrm{~g} / \mathrm{cc})\end{array}$} \\
\hline & 0.75 & $22 \%$ & $26 \%$ & $30 \%$ & $33 \%$ & $35 \%$ & $32 \%$ & $33 \%$ & $33 \%$ \\
\hline & 1.00 & $30 \%$ & $33 \%$ & $35 \%$ & $37 \%$ & $38 \%$ & $36 \%$ & $38 \%$ & $38 \%$ \\
\hline & 1.25 & $32 \%$ & $33 \%$ & $35 \%$ & $36 \%$ & $38 \%$ & $35 \%$ & $37 \%$ & $38 \%$ \\
\hline & 1.50 & $30 \%$ & $31 \%$ & $33 \%$ & $35 \%$ & $36 \%$ & $33 \%$ & $35 \%$ & $36 \%$ \\
\hline & 2.00 & $23 \%$ & $24 \%$ & $26 \%$ & $28 \%$ & $29 \%$ & $26 \%$ & $28 \%$ & $28 \%$ \\
\hline \multicolumn{10}{|c|}{$\begin{array}{l}\text { Front 1m } \\
\text { Midpoint - BN lining }(3.45 \mathrm{~g} / \mathrm{cc})\end{array}$} \\
\hline & 0.75 & $-16 \%$ & $-14 \%$ & $-13 \%$ & $-12 \%$ & $-11 \%$ & $-13 \%$ & $-13 \%$ & $-12 \%$ \\
\hline & 1.00 & $-11 \%$ & $-11 \%$ & $-10 \%$ & $-8 \%$ & $-7 \%$ & $-8 \%$ & $-7 \%$ & $-7 \%$ \\
\hline & 1.25 & $-11 \%$ & $-10 \%$ & $-9 \%$ & $-7 \%$ & $-6 \%$ & $-8 \%$ & $-7 \%$ & $-6 \%$ \\
\hline & 1.50 & $-11 \%$ & $-10 \%$ & $-9 \%$ & $-8 \%$ & $-7 \%$ & $-9 \%$ & $-8 \%$ & $-8 \%$ \\
\hline & 2.00 & $-15 \%$ & $-15 \%$ & $-14 \%$ & $-14 \%$ & $-13 \%$ & $-17 \%$ & $-17 \%$ & $-17 \%$ \\
\hline \multicolumn{10}{|c|}{$\begin{array}{l}\text { Front } 1 \mathrm{~m} \\
\text { Midpoint }-\mathrm{B}_{4} \mathrm{C} \text { lining }(2.52 \mathrm{~g} / \mathrm{cc})\end{array}$} \\
\hline & 0.75 & $8 \%$ & $12 \%$ & $15 \%$ & $17 \%$ & $19 \%$ & $16 \%$ & $17 \%$ & $17 \%$ \\
\hline & 1.00 & $16 \%$ & $19 \%$ & $20 \%$ & $22 \%$ & $23 \%$ & $21 \%$ & $23 \%$ & $23 \%$ \\
\hline & 1.25 & $18 \%$ & $19 \%$ & $21 \%$ & $22 \%$ & $24 \%$ & $21 \%$ & $23 \%$ & $24 \%$ \\
\hline & 1.50 & $17 \%$ & $18 \%$ & $19 \%$ & $21 \%$ & $23 \%$ & $20 \%$ & $22 \%$ & $23 \%$ \\
\hline & 2.00 & $12 \%$ & $13 \%$ & $14 \%$ & $16 \%$ & $17 \%$ & $14 \%$ & $16 \%$ & $16 \%$ \\
\hline
\end{tabular}




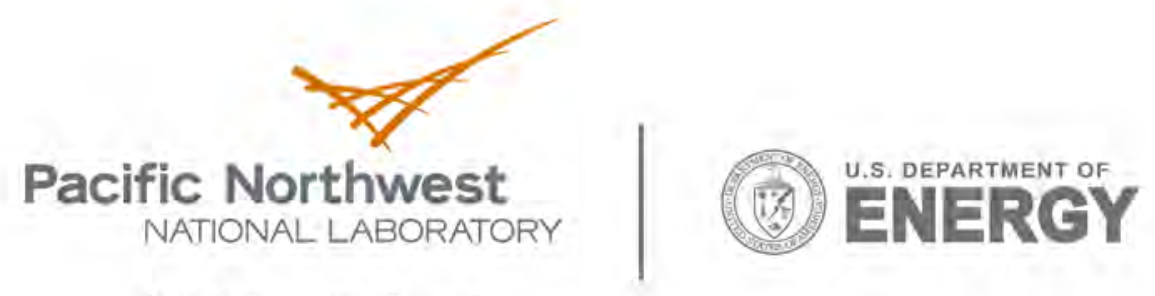

902 Battelle Boulevard

P.O. Box 999

Richland, WA 99352

1-888-375-PNNL (7665)

www.pnl.gov 